University of Wollongong

Research Online

Australian Institute for Innovative Materials -

Papers

Australian Institute for Innovative Materials

$1-1-2014$

\title{
Enhanced performance of dye-sensitized solar cells using carbazole- substituted di-chromophoric porphyrin dyes
}

Long Zhao

University of Wollongong, Iz796@uowmail.edu.au

Pawel Wagner

University of Wollongong, pawel@uow.edu.au

Anastasia Elliott

University of Otago

Matthew Griffith

University of Wollongong, mjg48@uow.edu.au

Tracey M. Clarke

University of Wollongong, tclarke@uow.edu.au

See next page for additional authors

Follow this and additional works at: https://ro.uow.edu.au/aiimpapers

Part of the Engineering Commons, and the Physical Sciences and Mathematics Commons

Research Online is the open access institutional repository for the University of Wollongong. For further information contact the UOW Library: research-pubs@uow.edu.au 


\title{
Enhanced performance of dye-sensitized solar cells using carbazole-substituted di-chromophoric porphyrin dyes
}

\begin{abstract}
The purpose of this work is to investigate the origin of improved photovoltaic performance of a series of di-chromophoric carbazole-substituted porphyrin dyes employed as sensitizers in dye-sensitized solar cells. Five di-chromophoric zinc porphyrin dyes with the same porphyrin core, a carbazole unit attached in the meso-position through a phenylethenyl linkage, and substituents spanning a range of electron affinities, in an attempt to tune the electronic level of the carbazole unit, have been synthesized (CZPs). Density functional theory (DFT) calculations predicted the nature of the electronic transitions observed in the CZP systems, showing a large degree of orbital mixing. In contrast, UV-vis absorption, resonance Raman spectroscopy and differential pulse voltammetry investigations suggested negligible interaction between the porphyrin and carbazole chromophores. Carbazole substitution led to a moderate increase in photon absorption intensity within the $\sim 300 \mathrm{~nm}$ to $400 \mathrm{~nm}$ wavelength region, a smaller but broader Soret band absorption and slightly increased photon absorption intensity in the $550 \mathrm{~nm}$ to $650 \mathrm{~nm}$ Q band region. Despite the rather small changes in light harvesting and negligible changes in the HOMO/LUMO electronic levels, the photovoltaic performance of the new dyes is increased by as much as $30 \%$ compared to the single chromophore Zn porphyrin dye 5-(4-(2-cyano-2-carboxyethenyl)phenyl-15-phenyl-10,20-bis(2,4,6-trimethylphenyl)porphyrinato zinc(ii) (ZP1), leading to over $6 \%$ power conversion efficiencies (PCEs). Both open circuit voltage (VOC) and short circuit current (JSC) have increased. The increased VOC is attributed to increased electron lifetimes due to a steric blocking effect. Analysis of the increased short circuit current ( $\triangle \mathrm{JSC}$ ) showed that only less than $10 \%$ of $\triangle J S C$ originates from increased light absorption under simulated air mass 1.5 illumination, while the rest of the improvements are attributed to a steric effect enhancing the electron injection efficiency. These results suggest that developing non-conjugated multichromophoric dyes can lead to simultaneous increases in both the photocurrent and the photovoltage of dye-sensitized solar cells. This journal is
\end{abstract}

\section{Keywords}

sensitized, dye, cells, carbazole, substituted, di, solar, chromophoric, performance, porphyrin, dyes, enhanced

Disciplines

Engineering | Physical Sciences and Mathematics

\section{Publication Details}

Zhao, L., Wagner, P., Elliott, A. B. S., Griffith, M. J., Clarke, T. M., Gordon, K. C., Mori, S. \& Mozer, A. J. (2014). Enhanced performance of dye-sensitized solar cells using carbazole-substituted di-chromophoric porphyrin dyes. Journal of Materials Chemistry A, 2 (40), 16963-16977.

\section{Authors}

Long Zhao, Pawel Wagner, Anastasia Elliott, Matthew Griffith, Tracey M. Clarke, Keith C. Gordon, Shogo Mori, and Attila Mozer 


\title{
Enhanced performance of dye-sensitized solar cells using carbazole-substituted di-chromophoric porphyrin dyes
}

\author{
Long Zhao, ${ }^{a}$ Pawel Wagner, ${ }^{a}$ Anastasia B. S. Elliott, ${ }^{b}$ Matthew J. Griffith, ${ }^{a}$ Tracey M. Clarke, ${ }^{a}$ \\ Keith C. Gordon, ${ }^{b}$ Shogo Mori ${ }^{c}$ and Attila J. Mozer*, ${ }^{a}$
}

The purpose of this work is to investigate the origin of improved photovoltaic performance of a series of di-chromophoric carbazole-substituted porphyrin dyes employed as sensitizers in dye-sensitized solar cells. Five di-chromophoric zinc porphyrin dyes with the same porphyrin core, a carbazole unit attached in the meso-position through a phenylethenyl linkage, and substituents spanning a range of electron affinities, in an attempt to tune the electronic level of the carbazole unit, have been synthesized (CZPs). Density functional theory (DFT) calculations predicted the nature of the electronic transitions observed in the CZP systems, showing a large degree of orbital mixing. In contrast, UV-vis absorption, resonance Raman spectroscopy and differential pulse voltammetry investigations suggested negligible interaction between the porphyrin and carbazole chromophores. Carbazole substitution led to a moderate increase in photon absorption intensity within the $\sim 300 \mathrm{~nm}$ to $400 \mathrm{~nm}$ wavelength region, a smaller but broader Soret band absorption and slightly increased photon absorption intensity in the $550 \mathrm{~nm}$ to $650 \mathrm{~nm} \mathrm{Q}$ band region. Despite the rather small changes in light harvesting and negligible changes in the HOMO / LUMO electronic levels, the photovoltaic performance of the new dyes is increased by as much as 30\% compared to the single chromophore Zn porphyrin dye 5-(4-(2-Cyano-2-carboxyethenyl)phenyl-15-phenyl10,20-bis(2,4,6-trimethylphenyl)porphyrinato zinc(II) (ZP1), leading to over $6 \%$ power conversion efficiencies (PCEs). Both open circuit voltage $\left(\mathrm{V}_{\mathrm{OC}}\right)$ and short circuit current $\left(\mathrm{J}_{\mathrm{SC}}\right)$ have increased. The increased $\mathrm{V}_{\mathrm{OC}}$ is attributed to increased electron lifetimes due to a steric blocking effect. Analysis of the increased short circuit current $\left(\Delta \mathrm{J}_{\mathrm{SC}}\right)$ showed that only less than $10 \%$ of $\Delta \mathrm{J}_{\mathrm{SC}}$ originates from increased light absorption under simulated air mass 1.5 illumination, while the rest of the improvements are attributed to a steric effect enhancing the electron injection efficiency. These results suggest that developing non-conjugated multichromophoric dyes can lead to simultaneous increases in both the photocurrent and the photovoltage of dye-sensitized solar cells.

\section{Introduction}

To increase the power conversion efficiency (PCE, $\eta$ ) of dye-sensitized solar cells (DSSCs), designing new molecules providing a simultaneous increase in short circuit current $\left(\mathrm{J}_{\mathrm{SC}}\right)$ and open circuit voltage $\left(\mathrm{V}_{\mathrm{OC}}\right)$ is desired. Higher $\mathrm{J}_{\mathrm{SC}}$ can be obtained by extending the light harvesting wavelength range, ${ }^{1,2}$ while higher $\mathrm{V}_{\mathrm{OC}}$ can be achieved by elongating electron lifetime. ${ }^{3,4}$ The former can be realized by extended delocalisation of the $\pi$-electrons leading to lower bandgaps, while increasing the electron lifetime can be accomplished primarily by preventing the accumulation of the oxidised form of the redox mediator (triiodide ions in this work) near the $\mathrm{TiO}_{2}$ interface (steric blocking effect). Modification to the chemical structure of the dyes inevitably affects both light harvesting and recombination kinetics. For example, increasing $\pi$ conjugation not only leads to increased light absorption, but also stronger dispersion forces between chromophore and triiodide ions leading to lower electron lifetime and $\mathrm{V}_{\mathrm{OC}}{ }^{5}$

This work investigates the origin of performance improvements of a series of carbazole-substituted di-chromophoric porphyrin dyes. While carbazole, due to its rather large bandgap, is not well suited for improving solar light harvesting, for this particular work it is shown to be a useful model compound with a spectral response complementary to the porphyrin absorption, so that increased light absorption and steric effects can be separately discussed.

Porphyrins are good candidates as photosensitizers. ${ }^{6,7}$ Some of the early work prior to 2004 is reviewed by Officer et al. ${ }^{8}$ More recent progresses have been reviewed by Imahori et al, ${ }^{9-13}$ Diau et al ${ }^{14-19}$ and Mozer et al. ${ }^{20-22}$

Since 2004, several zinc porphyrin monomers with respectable efficiency have been developed. Three of the best performing dyes were $\beta$-substituted zinc porphyrins 4-((E) -(2-(5,10,15,20-(tetra3,5-dimethylphenyl)porphyrinato zinc(II)-2-yl)ethen-1yl)benzoic acid (Zn2), ${ }^{23}$ 1-cyano-2-(5,10,15,20-tetraphenylporphyrinato zinc(II)-2-yl)-acrylic acid (GD1) ${ }^{24}$ and 3 (5,10,15,20-tetra(3,5-dimethylphenyl)porphyrinato zinc(II)-2-yl)-2-propen-1-ylidenepropandioic acid (GD2). ${ }^{25}$ Imahori et al designed high performance porphyrin sensitizers primarily by experimenting on the anchoring moieties at meso-position of porphyrins. ${ }^{9-11}$ For example, using a quinoxaline-fused spacer in 5,10,15,20-tetrakis(2,4,6-trimethylphenyl)-6'carboxyquinoxalino(2,3- $\beta$ )porphyrinato zinc (II) (ZnQMA) a PCE of 5.2\% was obtained. ${ }^{12}$ The influence of molecular size and electronic coupling between the porphyrin core and the $\mathrm{TiO}_{2}$ was also examined, with the highest power conversion efficiency of $4.6 \%$ achieved by 5-(4-carboxyphenyl)-10,15,20-tris(2,4,6-trimethylphenyl)porphyrinato zinc(II). ${ }^{13}$

The importance of electronic coupling and the distance between carboxylic acid groups and the $\mathrm{TiO}_{2}$ surface was studied by Kim et al, suggesting the former influenced electron injection and the latter affected recombination. ${ }^{26}$ The concept of a Donor- $\pi$-conjugated bridge-Acceptor (D- $\pi-A)$ structure was employed to modulate the highest occupied molecular orbital (HOMO) level and lowest unoccupied molecular orbital (LUMO) level, to induce a red-shift of the absorption bands. ${ }^{14-16,19}$ One of the highly cited record DSSC performance of $12.3 \%$ using a $\mathrm{Co}^{2+} / \mathrm{Co}^{3+}$ containing liquid electrolyte was achieved by a mixture of zinc porphyrin dye YD2-o-C8 and an organic dye. ${ }^{17}$ More recently, a single porphyrin dye SM315 with a D- $\pi-A$ structure achieved $13 \% .^{27}$

The idea of multi-chromophoric porphyrin dyes have been increasingly popular for DSSCs, partially due to their perceived benefits in extending the light harvesting range in a manner analogous to natural light harvesting in plants. The term 3-D 
light harvesting was coined to describe covalently linked chromophores within a single sensitizer attached to the electron acceptor $\mathrm{TiO}_{2}$, contrasting the monolayer coverage of single chromophore / single dye arrangements of more conventional DSSC designs. $8,20,28$ Two major trends in multi-chromophoric dye designs are emerging. In the first approach, combining two distinct chromophores using conjugated linkers leads to new absorption bands that extend the absorption range. This approach is analogous to the $\mathrm{D}-\pi$-A type asymmetric dye concept above. For example, two diporphyrin heterodimers with enhanced spectral response on $\mathrm{TiO}_{2}$ films were reported by Koehorst and co-workers in 2000, however, performance of DSSCs was not mentioned. ${ }^{29}$ Diporphyrin sensitizers (YDD0-YDD3) synthesized by Mai et al. exhibited much broader absorption wavelength range than the single porphyrin YD0. ${ }^{18}$ However, their performance in DSSCs was not impressive. More recently, a $\pi$-conjugated $N$-fused carbazole-zinc porphyrin-free-based porphyrin triad, coded as DTBC, showed an absorption on $\mathrm{TiO}_{2}$ film extending to $800 \mathrm{~nm}$, while the $\mathrm{V}_{\mathrm{OC}}$ was less than $0.6 \mathrm{~V} .{ }^{30}$ Chromophores "antennas", e.g. borondipyrromethene (BODIPY) and diketopyrrolopyrrole (DPP) derivatives, attached to a zinc porphyrin dyad through axial ligation on the zinc core resulted in a $\sim 25 \%$ increase in the photocurrent. The enhancement was attributed to energy transfer from the antenna to the porphyrin. The $\mathrm{V}_{\mathrm{OC}}$ was quite moderate at $0.575 \mathrm{~V}{ }^{31}$ This latter work exemplifies a possible weakness of the multichromophore approach. Extending the $\pi$-conjugation often leads to further planarization of the molecule, causing a tendency for aggregation. ${ }^{18,32,33}$ Due to the larger $\pi$-conjugated system, the polarizability of the $\pi$ electrons may also increase, leading to stronger dispersion forces, shorter electron lifetime and lower $\mathrm{V}_{\text {OC. }}$.

The second approach to multi-chromophoric dyes uses a non-conjugated arrangement of the chromophores. One of the first demonstrations of this approach showed efficient electron injection from both porphyrins in a porphyrin dimer (P10) with a non-conjugated linker. ${ }^{20}$ The two porphyrins showed nearly identical electronic structures therefore the main beneficial effect was the doubling of the molar extinction coefficient and the ability to achieve increased power conversion efficiencies using thin $\mathrm{TiO}_{2}$ electrodes. While this latter approach generally does not afford the extension of the visible light absorption range due to negligible electronic coupling through the non-conjugated linker unit, increased electron lifetime through a steric blocking effect has been clearly demonstrated.

A series of meso-meso linked porphyrin dimers were reported by Park et al. ${ }^{34}$ The highest PCE of $4.2 \%$ was achieved by a poly(ethylene glycol)-modified dimer (PEG-2b-bd-Zn2), which showed higher solubility in dye solution. Further optimisation P10 non-conjugated porphyrin dimer described above ${ }^{21}$ has yielded a $5.5 \%$ DSSC, which is among the best results for multi-chromophoric DSSC dyes confirming the viability of this second design approach. The above discussion on the viability of the two approaches highlights the fact that some increased clarity is needed to separate the effect of increased light harvesting from steric effects influencing charge injection and charge collection efficiencies.

Therefore, this work aims to further investigate the viability of the second, non-conjugated di-chromophore approach. By using carbazole units primarily absorbing in the $300 \mathrm{~nm}$ to $400 \mathrm{~nm}$ wavelength ranges where porphyrin absorption is weak, the increased light harvesting effect can be separated from a steric effect related to the generally more bulky structure of dichromophoric dyes. The results suggest that the steric effect can play an important role in enhancing photovoltaic performance, in our case contributing to the majority of the improvement. UV-vis and resonance Raman spectroscopy, along with differential pulse voltammetry, are employed to investigate the electronic structure of the compounds in solution. Detailed light harvesting, incident and absorbed photon to current conversion efficiencies (LHE/IPCE/APCE) and transient photovoltage and photocurrent investigations are used to distinguish between the light enhancement and steric effects.

\section{Experimental}

\section{Chemical structure, synthesis and characterization}

The following abbreviations are used throughout the manuscript: 5-(4-(2-Cyano-2-carboxyethenyl)phenyl-15-(4-(2-(6-(4(N,N-diphenylamino)phenyl-9-(3,7-dimethyloctyl)-9H-carbazol-3-yl)ethenyl)phenyl-10,20-bis(2,4,6-

trimethylphenyl)porphyrinato zinc (II) (CZP1); 5-(4-(2-Cyano-2-carboxyethenyl)phenyl-15-(4-(2-(6-(4trifluoromethylphenyl)-9-(3,7-dimethyloctyl)-9H-carbazol-3-yl)ethenyl)phenyl-10,20-bis(2,4,6-

trimethylphenyl)porphyrinato zinc (II) (CZP2); 5-(4-(2-Cyano-2-carboxyethenyl)phenyl-15-(4-(2-(6-(4-methylphenyl)-9(3,7-dimethyloctyl)-9H-carbazol-3-yl)ethenyl)phenyl-10,20-bis(2,4,6-trimethylphenyl)porphyrinato zinc (II) (CZP3); 5-(4(2-Cyano-2-carboxyethenyl)phenyl-15-(4-(2-(6-(4-methoxylphenyl)-9-(3,7-dimethyloctyl)-9H-carbazol-3-

yl)ethenyl)phenyl-10,20-bis(2,4,6-trimethylphenyl)porphyrinato zinc (II) (CZP4); 5-(4-(2-Cyano-2-carboxyethenyl)phenyl15-(4-(2-(6-(3-trifluoromethylphenyl)-9-(3,7-dimethyloctyl)-9H-carbazol-3-yl)ethenyl)phenyl-10,20-bis(2,4,6-

trimethylphenyl)porphyrinato zinc (II) (CZP5); 5-(4-(2-Cyano-2-carboxyethenyl)phenyl)-15-(4-methylphenyl)-10,20bis(2,4,6-trimethylphenyl)porphyrinato zinc(II) (ZP1); 6-(4-(N,N-diphenylamino)phenyl)-(9-(3,5-dimethyloctyl)carbazole-3carboxaldehyde (Cb1); 9-(3,7-dimethyloctyl)-6-methyl-3-(4-trifluoromethylphenyl)carbazole(Cb2).

The chemical structures are displayed in Table 1 and the synthesis is described in SI A.

Density functional theory (DFT) calculations were obtained using the Gaussian 09 software package. ${ }^{35}$ Structural modelling, vibrational mode and electronic transition calculations were performed using the B3LYP functional and 6-31G(d) basis set with a LANL2DZ effective core potential for $\mathrm{Zn}$. To increase computational efficiency the branched alkyl chain on the carbazole was omitted. The accuracy of the calculations was checked by calculating the mean absolute deviation (MAD) between experimental and calculated Raman bands. In all cases these were found to be less than $10 \mathrm{~cm}^{-1}$, indicating a satisfactory calculation. ${ }^{36-40}$

FT-Raman spectra $\left(\lambda_{\mathrm{ex}}=1064 \mathrm{~nm}\right)$ were obtained from solid samples using a Bruker Equinox-55 FT-interferometer with an FRA106/5 Raman accessory and D418T liquid-nitrogen-cooled Germanium detector. A ND:YAG laser operating at 120 $\mathrm{mW}$ was used to excite the sample. The Bruker OPUS v5.5 software package was used to produce spectra from 512 scans at a resolution of $4 \mathrm{~cm}^{-1}$. FT-Raman spectra of pure solid CB1 $\left(\lambda_{\mathrm{ex}}=830 \mathrm{~nm}\right)$ were collected using an i-Raman spectrometer (B\&WTEK inc., Newark, DE) operating at $155 \mathrm{~mW}$. Spectra were produced using BWSpec v3.27 software and an accumulation time of 32 seconds. 
Resonance Raman spectroscopy was performed on solutions with concentrations of $1 \mathrm{mM}$ in dichloromethane (DCM, $99.9 \%$, Sigma-Aldrich). The experimental procedures are described elsewhere. ${ }^{41-43}$ Samples were excited at a number of wavelengths; 351, 364, 407, 413, 448 and $458 \mathrm{~nm}$, using laser powers of between 20-50 mW with a spot size of $500 \mu \mathrm{m}$. At longer wavelengths emission became excessive and Raman signals were not identifiable. ${ }^{42,44}$

UV-visible (UV-vis) absorption spectroscopy was performed in both DCM (99.8\%, Chem-Supply) and dimethylformamide (DMF, 99.99\%, Honeywell) solutions using a Shimadzu UV-3600 spectrophotometer using $1 \mathrm{~cm}$ length quartz cuvettes and $1 \mu \mathrm{M}$ solutions.

Differential Pulse Voltammetry (DPV) was carried out using an eDAQ (BVI) instrument. All compounds were dissolved in DCM. The concentration was $0.5 \mathrm{mM}$ and $0.1 \mathrm{M}$ for the dye and tetrabutylammonium perchlorate (TBAP, 99.0\%, Fluka) supporting electrolyte, respectively. DCM was re-purified by going through a column of activated alumina. Prior to each experiment, the solvent was purged with dry argon for 30 minutes, and placed in a glove bag (Atmosbag, Sigma-Aldrich). Measurements were performed using a Pt wire with $0.5 \mathrm{~mm}$ diameter as the working electrode (WE), Pt mesh as the counter electrode (CE) and a pseudo $\mathrm{Ag} / \mathrm{AgCl}$ wire as the reference electrode (RE). The $\mathrm{RE}$ potential was calibrated using $1 \mathrm{mM}$ freshly prepared ferrocene/ferrocenium couple $\left(\mathrm{Fc} / \mathrm{Fc}^{+}, 98 \%\right.$, Aldrich) in the same solution. The Pt wire was polished with polishing paper prior to use, and sealed by an approximately $10 \mathrm{~mm}$ glass tube to leave a specified area of $6.6 \mathrm{~mm}^{2}$. Scan rate was $100 \mathrm{mV} \mathrm{s}^{-1}$. For oxidations (positive scan), the pulse amplitude was $+(-) 25 \mathrm{mV}$, and the potential step (step E) was $+(-) 10 \mathrm{mV}$.

Dye-sensitized solar cells (DSSC) fabrication and characterization

Both photoanode and CE consisted of fluorine doped tin oxide glass (FTO glass, $3 \mathrm{~mm}, 8 \Omega$ /square, Nippon Sheet Glass) substrate. A platinum layer was coated on the $\mathrm{CE}$ surface by a thermal decomposition method. $10 \mathrm{mM}$ platinic acid $\left(\mathrm{H}_{2} \mathrm{PtCl}_{6}\right.$, $38 \% \mathrm{Pt}$, Sigma-Aldrich) in ethanol was used as the precursor. One drop of the solution was needed for a CE with the size 1.7 $\mathrm{cm} \times 2 \mathrm{~cm}$, which was sintered at $400{ }^{\circ} \mathrm{C}$ for 30 minutes.

Photoanode preparation. First, an approximately $100 \mathrm{~nm} \mathrm{TiO}_{2}$ compact layer was prepared by spray coating of titanium diisopropoxide bis(acetylacetonate) (TAA, 75\% in isopropanol, Aldrich). The TAA was dissolved in ethanol (99.8\%, SigmaAldrich) with a ratio of 1:9 (vol.). The precursor was sprayed onto the FTO glass held at $400{ }^{\circ} \mathrm{C}$, and kept for another 30 minutes on the hotplate. The mesoporous $\mathrm{TiO}_{2}$ layer was screen-printed. The $\mathrm{TiO}_{2}$ thickness was controlled by changing the screen mesh density and the number of printing cycles. For thin films of $\sim 3 \mu \mathrm{m}$ (Figure 6(a)), a transparent $\mathrm{TiO}_{2}$ paste (18NRT, Dyesol) was used. For thick films (Figure 6(b)), a scattering layer (WER2-O, Dyesol) was also introduced. The sintering program for the printed $\mathrm{TiO}_{2}$ layer was: $325^{\circ} \mathrm{C}$ for 5 minutes, $375{ }^{\circ} \mathrm{C}$ for 5 minutes, $450{ }^{\circ} \mathrm{C}$ for 30 minutes, $500{ }^{\circ} \mathrm{C}$ for 15 minutes, followed by cooling down to the room temperature. The sintered $\mathrm{TiO}_{2}$ films were immersed in $0.02 \mathrm{M} \mathrm{TiCl}_{4}$ solution $\left(99.0 \%\right.$, Sigma-Aldrich) in water at $70^{\circ} \mathrm{C}$ for 30 minutes. After being rinsed by water and ethanol, the films were heated to $500{ }^{\circ} \mathrm{C}$, and held for 30 minutes.

$1.3 \mathrm{~cm} \times 1.7 \mathrm{~cm}$ of pre-cut $\mathrm{TiO}_{2} /$ FTO glass substrates were immersed into a dye solution for 1.5 hours to achieve dyesensitization. Dye solutions for devices displayed in Fig. 6, Fig. 7, Fig. 8 and Fig. 9 used tetrahydrofuran (THF, 97\%, Ajax) as solvent $(0.2 \mathrm{mM})$. To effectively employ chenodeoxycholic acid (CDCA, Solaronix) as co-adsorber (Fig. 10), ethanol was used. The concentration of CDCA was $2 \mathrm{mM}$. The electrolyte consisted of $0.6 \mathrm{M}$ 1,2-dimethyl-3-propylimidazolium iodide (DMPII, synthesized in house), 0.1 M LiI (99.9\%, Aldrich), $0.05 \mathrm{M} \mathrm{I}_{2}$ (99.99\%, Aldrich), $0.5 \mathrm{M}$ tert-butylpyridine (t-BP, 96\%, Aldrich) in acetonitrile (AN, 99.8\%, Sigma-Aldrich): valeronitrile (VN, 99.5\%, Sigma-Aldrich)=85:15 (Vol.). Electrolyte was backfilled using a vacuum pump with the pressure 65 mbar.

A 20-minute light soaking process was applied to the finished devices before device measurements. ${ }^{45}$

Current density-voltage (J-V) measurements were performed using a simulated $100 \mathrm{~mW} \mathrm{~cm}$-2 air mass $1.5 \mathrm{G}$ solar simulation (Newport) and a Keithley 2400 source measure unit. A $6 \mathrm{~mm} \times 6 \mathrm{~mm}$ mask was used to define the illumination area. The size of the sensitized area was $4 \mathrm{~mm} \times 4 \mathrm{~mm}$.

Incident photon-to-current conversion efficiency (IPCE) was recorded using a $300 \mathrm{~W}$ Xe lamp coupled to a monochromator with long pass filters. The light output was focused on a $\sim 2 \mathrm{~mm}^{2}$ spot with additional optics (Newport). The photocurrent response of the devices was recorded in $5 \mathrm{~nm}$ wavelength steps using a Keithley 2400 . The measured currents were referenced to a calibrated Si diode (PECCELL).

Light harvesting efficiency (LHE) measurements of the sensitized films was determined using a Shimadzu UV-3600 spectrophotometer. Microscope cover slides were placed over the sensitized films, and a drop of the electrolyte was injected into the space between the photoanode and the cover slide to mimic device conditions during IPCE measurements. Light harvesting efficiency (LHE) of the dyes on $\mathrm{TiO}_{2}$ was calculated using the procedure described in Ref. ${ }^{46}$.

Absorbed photon-to-current conversion efficiency (APCE) was calculated from IPCE and LHE values according to Equation 1:

$$
\operatorname{APCE}(\lambda)=\frac{\operatorname{IPCE}(\lambda)}{\operatorname{LHE}(\lambda)}=E_{\text {inj }}(\lambda) \times E_{\text {coll }}(\lambda)
$$

where $E_{\text {inj }}$ is electron injection efficiency and $E_{\text {coll }}$ is charge collection efficiency.

Stepped light-induced measurements of photocurrent and photovoltage (SLIM-PCV) were used to determine electron lifetime $(\tau)$ and electron diffusion coefficient (D). ${ }^{47}$ Measurements were taken after 20 minutes of light soaking of the freshly prepared DSSCs under $100 \mathrm{~mW} \mathrm{~cm}$-2 AM 1.5 illumination. A $635 \mathrm{~nm}$ diode laser was employed as the light source; by varying the laser intensity, $\mathrm{J}_{\mathrm{SC}}$ or $\mathrm{V}_{\mathrm{OC}}$ decays were obtained. A multimeter (ADCMT 7461A) was employed to record the current or voltage signal. For electron lifetime measurements, the laser intensity was turned down to give a less than $1 \mathrm{mV}$ change in the photovoltage. For electron diffusion coefficient measurements, the laser intensity was reduced to obtain less than $10 \%$ change in the photocurrent. Electron density (ED) in $\mathrm{TiO}_{2}$ films was determined by a charge extraction method. ${ }^{48}$ The laser intensity was switched off completely, while the device was simultaneously switched from open circuit to short circuit using a fast switch (AsamaLab) to measure charge density at open circuit condition.

Electron density (ED) at short circuit condition was determined by switching off the laser light while keeping the device at short circuit. The value of $\tau$ at short circuit condition was calculated by extrapolating $\tau$ versus $\log$ (ED) measured at open 
circuit to the electron density determined at short circuit condition. We note the above extrapolation method assumes that non-uniform electron distribution at short circuit conditions does not significantly affect the electron lifetime at short circuit. While this has been shown to be valid in some cases, ${ }^{49-51}$ the validity of this assumption has not been specifically tested for our devices.

The electron diffusion length (L) was obtained using equation 2:

$$
L=\sqrt{D \tau}
$$

The amount of dye loading on $\mathrm{TiO}_{2}$ was determined by desorbing the dyes from the semiconductor using $0.1 \mathrm{M}$ tetrabutylammonium hydroxide solution (TBAOH, $40 \mathrm{wt} . \%$ in water, Fluka) in DMF.

\section{Results}

\section{Chemical structure}

The structures of the di-chromophoric porphyrin dyes are shown in Table 1. Five dyads (CZP1 to CZP5) contain a zinc porphyrin chromophore with a cyanoacrylic acid anchor, and a carbazole unit with a branched alkyl chain attached to the porphyrin core through a phenylethenyl linker at the meso-position of the porphyrin.

The substituents at the end of the carbazole include phenyl groups with varying electron withdrawing/donating abilities. The triphenylamine (TPA), methylphenyl and methoxylphenyl moieties of CZP1, CZP3 and CZP4 respectively are electron donating groups, while the trifluoromethylphenyl moieties of CZP2 and CZP5 are electron withdrawing groups. CZP1 is the bulkiest as it contains the largest TPA unit.

For comparison, a porphyrin (ZP1) and two carbazole compounds (Cb1 and $\mathrm{Cb} 2$ ) were also prepared (Table 1). The structure of ZP1 is similar to the porphyrin core of the CZPs. Cb1 and Cb2 are similar to the carbazole part of CZP1 and $\mathrm{CZP} 2$, respectively, with different substituents at the 2-position of carbazole.

Table 1. Molecular structures of compounds

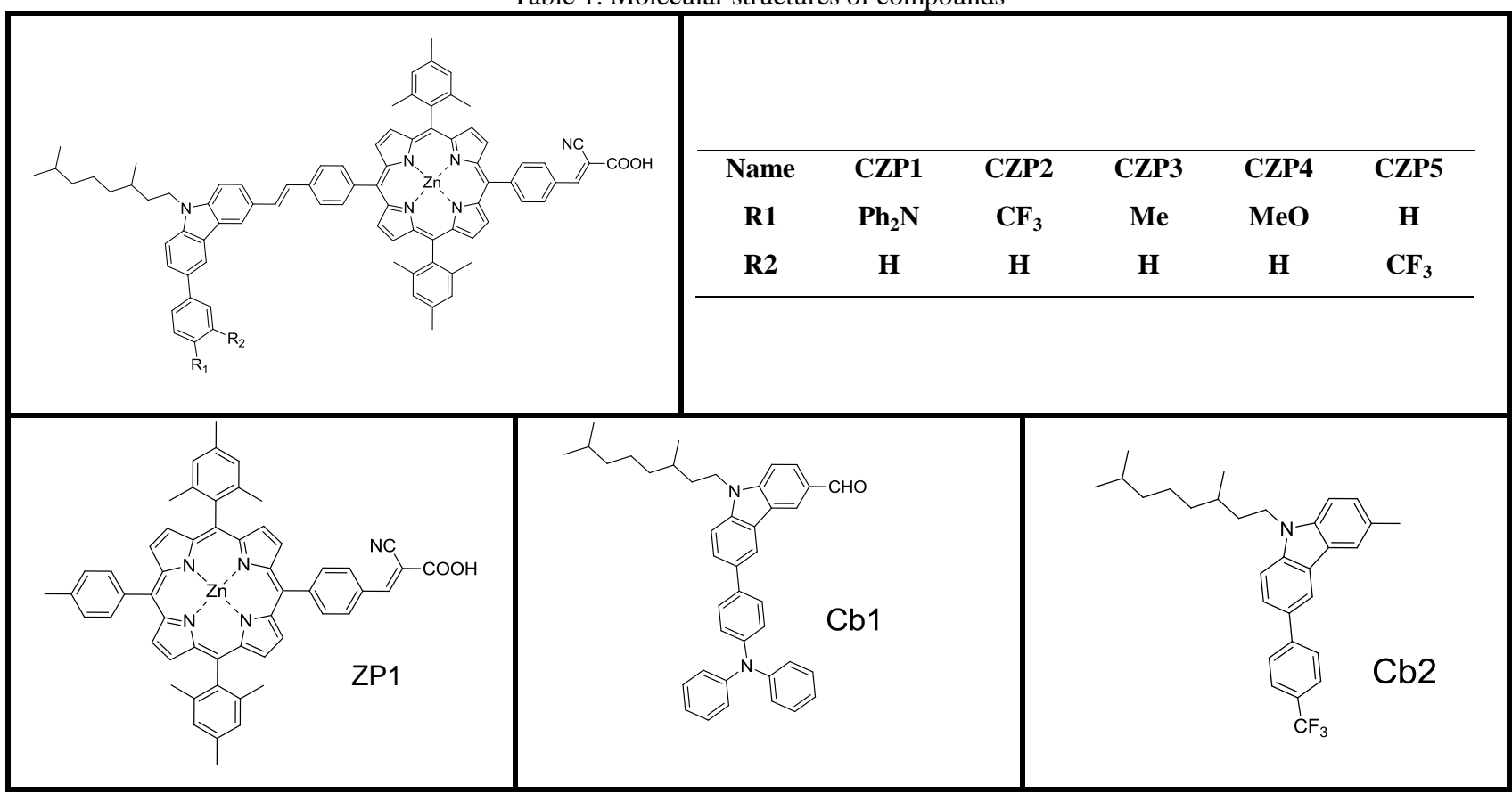

II. UV-visible absorption spectroscopy

The molar extinction coefficients $(\varepsilon)$ of the compounds are shown in Fig. 1 in (a) dichloromethane (DCM) and (b) dimethylformamide (DMF).

In both DCM and DMF, the six porphyrins show a mid-intensity band around $270-370 \mathrm{~nm}$, a strong Soret band at $\sim 420 \mathrm{~nm}$, and weaker Q bands between 530 and $630 \mathrm{~nm}$. The $\varepsilon$ maxima at the Soret band show a $\sim 30 \%$ increase and appear sharper in DMF compared to in DCM. The $\varepsilon$ of the first $Q$ band (at 551-562 nm) show similar values in DMF and DCM, while in the second Q band at 594-605 nm, it is 70\% higher for the porphyrin dyads in DMF and 100\% higher for ZP1. The oscillator strength calculated from the integrated area encompassing the Soret band is approximately $10 \%$ more in DMF than in DCM, while the integrated area of the Q bands showed a 15 to $40 \%$ increase in DMF (see Table S1).

Compared to ZP1, the CZPs show increased absorbance in the 270-370 nm wavelength range in both solvents. Light absorption by the carbazole moieties $\mathrm{Cb} 1$ and $\mathrm{Cb} 2$ are dominant at this wavelength range for the CZPs. CZP1, with carbazole-TPA unit, absorbs slightly more at $320-380 \mathrm{~nm}$ compared to the other CZPs due to increased light absorption by the TPA unit.

The $\varepsilon$ attributed to porphyrin absorption also differs between CZPs and ZP1. ZP1 achieves a 5-15\% higher maximum $\varepsilon$ in the Soret band than that of CZPs $\left(2.5-2.9 \times 10^{5} \mathrm{M}^{-1} \mathrm{~cm}^{-1}\right.$ in DCM and 3.5-3.8 $\times 10^{5} \mathrm{M}^{-1} \mathrm{~cm}^{-1}$ in DMF). An approximately $10 \mathrm{~nm}$ broadening of the Soret band and a 20 40\% higher maximum $\varepsilon$ in the Q bands are observed for CZPs relative to ZP1. The 
oscillator strength in both the Soret and Q bands show a 20 40\% increase for CZPs compared to ZP1 in both DCM and DMF (see Table S1).
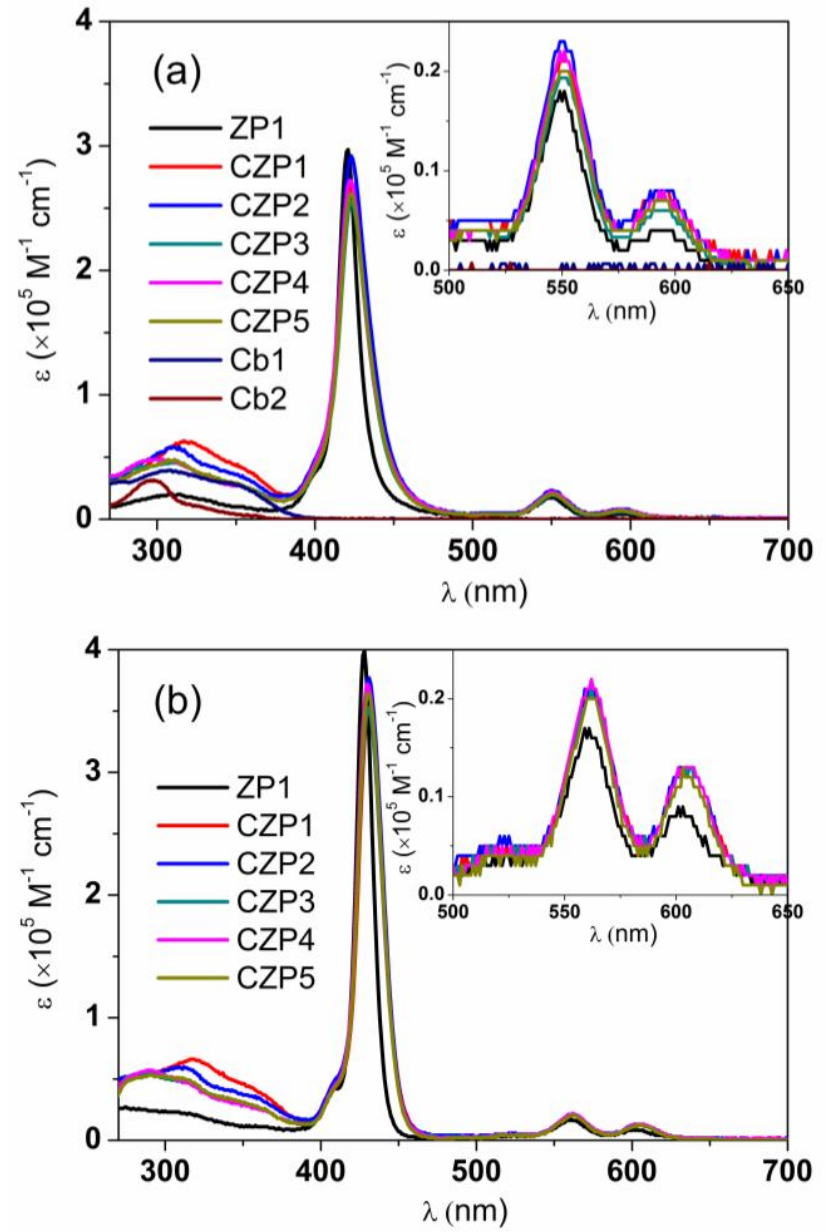

Figure 1. Molar extinction coefficient of the compounds measured in (a) DCM; (b) DMF

\section{Electrochemical properties}

The reduction / oxidation reactions measured by differential pulse voltammetry (DPV) of ZP1, CZP1 to CZP5, Cb1 and Cb2 dissolved in DCM are shown in Fig. 2(a) and Fig. 2(b), respectively. The peak potentials and onset potentials of the compounds are listed in Table S2. The potenials are referenced to the standard electrochemical potential of the $\mathrm{Fc} / \mathrm{Fc}^{+}$redox couple measured using the same reference electrode and solvent.

Two reduction reactions are observed in Fig. 2(a) in the potential window $-1 \mathrm{~V}$ to $-2.30 \mathrm{~V}$ vs Fc/Fc ${ }^{+}$for the porphyrins at $1.86 \mathrm{~V}$ and at $-2.20 \mathrm{~V}$, without any significant difference between the porphyrin compounds observed. The carbazole moieties, $\mathrm{Cb} 1$ and $\mathrm{Cb} 2$, do not show any reduction reactions in the measured potential window.

Two oxidation reactions are observed for ZP1 (Fig. 2(b)), both of which are attributed to porphyrin oxidation in two oneelectron oxidation processes. The carbazole moiety $\mathrm{Cb} 2$ shows an anodic peak at $\sim+0.78 \mathrm{~V} \mathrm{vs} \mathrm{Fc/Fc}{ }^{+}$, which is consistent with a reported $+1.20 \mathrm{~V}$ vs. $\mathrm{SCE}^{52}$ in acetonitrile with a similar carbazole structure. The second anodic feature of the carbazole unit $\mathrm{Cb} 2$ is observed at $\sim+1.05 \mathrm{~V}$ vs $\mathrm{Fc} / \mathrm{Fc}^{+}$exhibiting an anodic current that is significantly lower than the anodic current in of the first oxidation peak. Attaching a TPA unit to the carbazole (Cb1) leads to lowering of the first oxidation potential to around $+0.41 \mathrm{~V}$ vs $\mathrm{Fc} / \mathrm{Fc}^{+}$. This value is in agreement with the reported $\sim+0.70 \mathrm{~V}$ vs. SCE for the tetraphenylbenzidine unit. ${ }^{53}$ The second oxidation of $\mathrm{Cb} 1$ is observed at $+0.75 \mathrm{~V}$ vs Fc/Fc ${ }^{+}$.

CZP1 shows two anodic peaks that are broadened and more than twice the intensity of the ZP1 peaks using the same solute concentrations. CZP2, CZP4 and CZP5 show four clearly distingushiable oxidation peaks, CZP3 shows three, while CZP1 shows only two (Fig. 2(b)). The first oxidation peak is nearly identical for ZP1 and the carbazole-containing porphyrins at $+0.30 \mathrm{~V}$ vs Fc/Fc ${ }^{+}$. The second oxidation peak of CZP2, CZP3, CZP4 and CZP5 shifts anodically by $50 \mathrm{mV}$ to $100 \mathrm{mV}$, while the third ones shift cathodically by $20 \mathrm{mV}$ to $50 \mathrm{mV}$ compared to the second oxidation peak of ZP1 (at $+0.60 \mathrm{~V}$ vs $\left.\mathrm{Fc} / \mathrm{Fc}^{+}\right)$. CZP2 and CZP5 show a fourth peak at $0.8 \mathrm{~V} \mathrm{vs} \mathrm{Fc} / \mathrm{Fc}^{+}$while it is at $+0.95 \mathrm{~V}$ vs $\mathrm{Fc} / \mathrm{Fc}^{+}$for $\mathrm{CZP} 4$. 

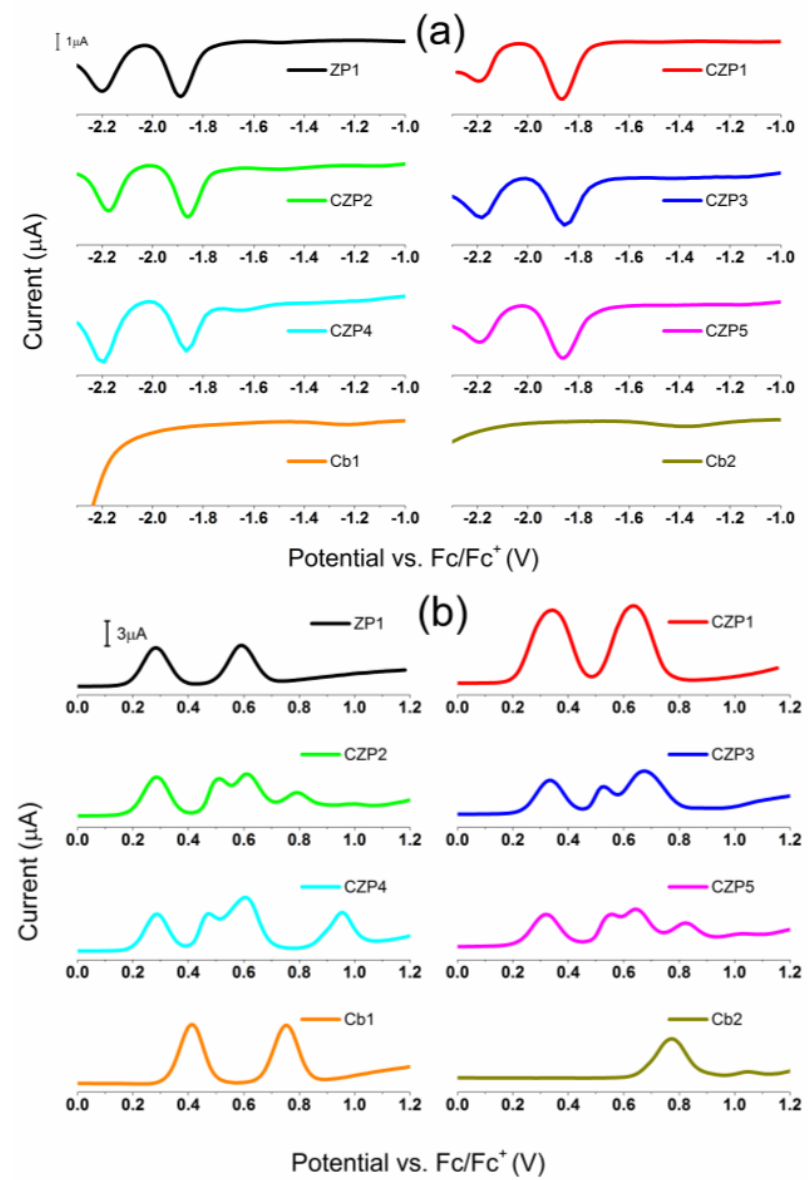

Figure 2. Differential pulse voltammograms of the investigated compounds, (a) negative scan; (b) positive scan. Sample concentration: $0.5 \mathrm{mM}$; solvent: DCM; supporting electrolyte: TBAP; Pt wire surface area: $6.6 \mathrm{~mm}^{2}$; scan rate: $100 \mathrm{mV} \mathrm{s}^{-1}$.

\section{Density functional theory calculations and resonance Raman spectroscopy}

DFT calculations were used to model the nature of vibrational modes that are observed in the Raman spectra while timedependent density functional theory (TD-DFT) informed on the observed electronic transitions.

The electronic absorption data (predicted and experimental) are reported in Table 2 for CZP1 as an exemplar of all samples. There is good qualitative agreement between the TD-DFT calculations and the observed spectra. The strong Soret-band observed experimentally at $425 \mathrm{~nm}$ is predicted at $398 \mathrm{~nm}$ with a large oscillator strength. Weaker bands are calculated at 455 and $607 \mathrm{~nm}$ and are observed at 550 and $590 \mathrm{~nm}$ respectively. The calculation provides the electronic configurations that contribute to the predicted transitions, however in these systems many of them show significant delocalization and the configurations do not allow for easy visualization of the transition. The change in electron transition densities (ETDs) permits this. In this analysis the molecule is factorized into structural groupings (R-group, carbazole, porphyrin and $\mathrm{CN}$ $\mathrm{COOH})$ as shown in Figure 3. The ETDs are also shown in Table 2 for CZP1 along with the other electronic data. The calculations predict that the transitions are not the simple porphyrin $(\lambda>400 \mathrm{~nm})$ or carbazole $(\lambda<400 \mathrm{~nm})$ based transitions observed for the separate moieties, indicating a significant amount of orbital mixing. The $\mathrm{R}$ group is also involved in a number of the transitions.

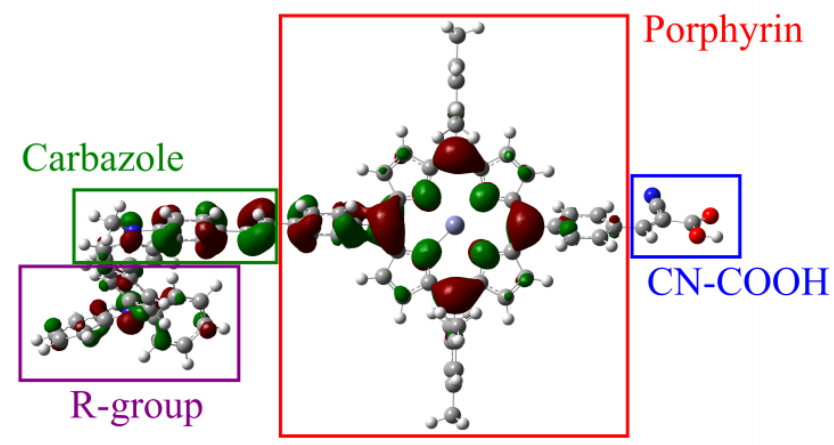

Figure 3. Schematic showing the grouping of atoms for electron transition density analysis of CZP1. 
All samples, CZP1-CZP5, exhibited similar Raman enhancements at specific excitation wavelengths. As an exemplar of the series, Figure 4 shows the Raman spectra for CZP1 at various wavelengths compared to the non-resonant spectrum $(830 \mathrm{~nm})$ of the carbazole Cb1.

The resonance Raman spectra show striking enhancement differences with $\lambda_{\mathrm{ex}}$. In the UV, $\lambda_{\mathrm{ex}}=351$ and $364 \mathrm{~nm}$, the most intense Raman bands are at 1599, 1613 and $1632 \mathrm{~cm}^{-1}$; as the $\lambda_{\text {ex }}$ is tuned to the violet, 407 and $413 \mathrm{~nm}$, very strong bands appear at 1233,1356 and $1549 \mathrm{~cm}^{-1}$. The spectrum changes further as the $\lambda_{\mathrm{ex}}$ is tuned further to the red, to $448 \mathrm{~nm}$; indeed at this point the exciting laser is essentially out of resonance and consequently the Raman spectrum is very similar to the nonresonant spectrum with $\lambda_{\mathrm{ex}}=1064 \mathrm{~nm}$. The non-resonance Raman spectrum of Cb1 shows strong bands at 1003, 1599 and $1613 \mathrm{~cm}^{-1}$.

The spectra coincident with the higher energy electronic transition, 351 and $364 \mathrm{~nm}$, are dominated by carbazole bands. This is consistent with DFT calculations, which predict significant ETD changes at the carbazole moiety for transitions to the blue of the Soret band. The strongly enhanced bands at 1172, 1426, 1576, 1599 and $1613 \mathrm{~cm}^{-1}$ are carbazole in nature. An example of a carbazole mode $\left(1599 \mathrm{~cm}^{-1}\right)$ is shown in Figure 5.

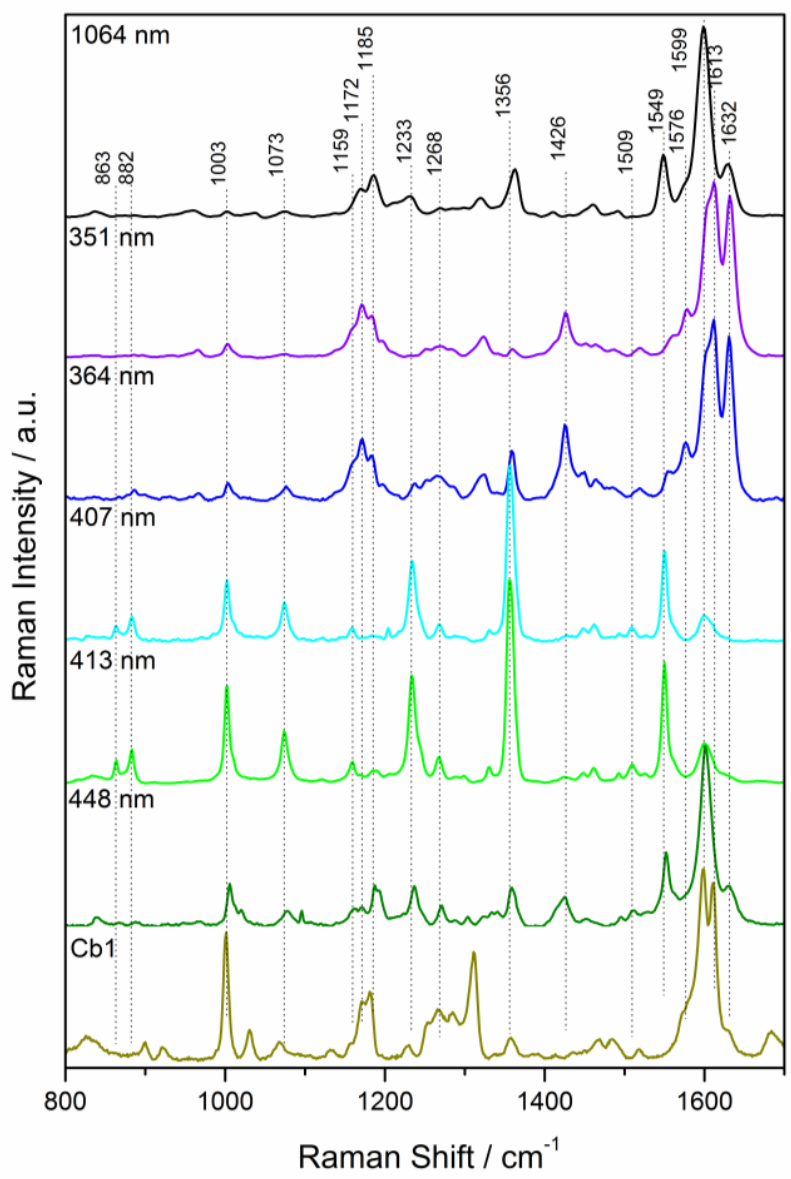

Figure 4. FT-Raman (solid, $\lambda_{\mathrm{ex}}=1064 \mathrm{~nm}$ ) and resonance Raman $\left(1 \mathrm{mM} \mathrm{CH}_{2} \mathrm{Cl}_{2}\right.$ solution, $\lambda_{\mathrm{ex}}=351-448 \mathrm{~nm}$ ) spectra of CZP1 and non-resonant (solid, $830 \mathrm{~nm}$ ) Raman spectrum of Cb1.

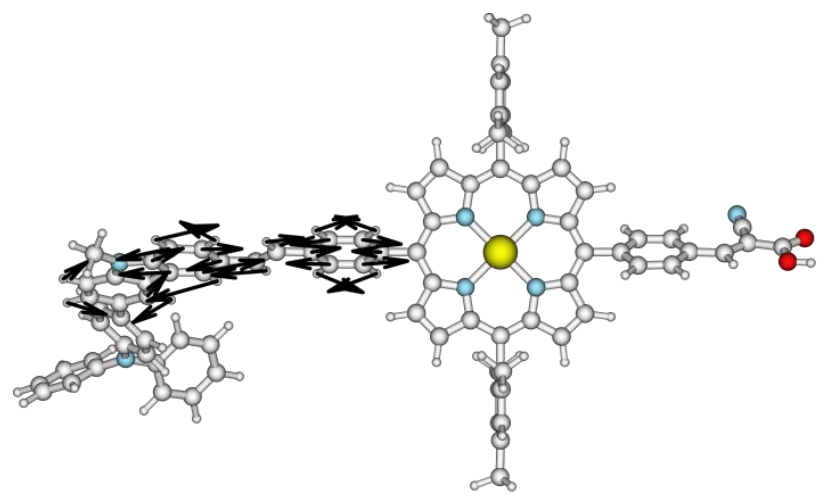

$1599 \mathrm{~cm}^{-1}$ 


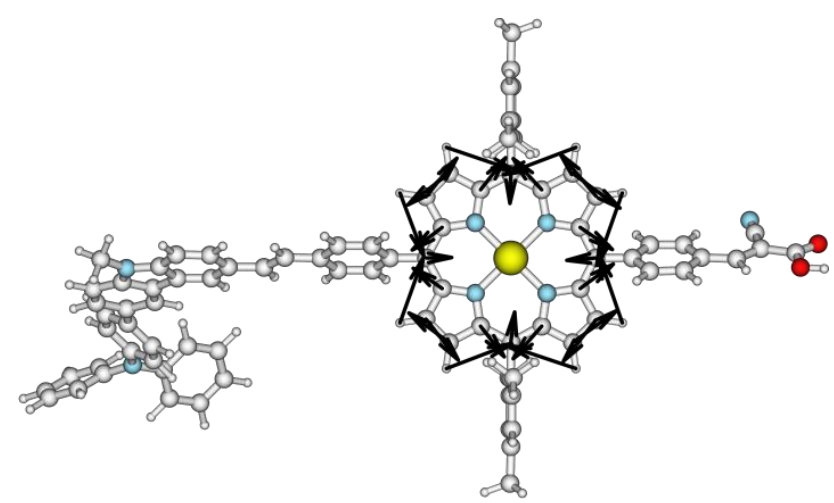

\section{$1549 \mathrm{~cm}^{-1}$}

Figure 5. Schematic of the vibrational modes observed in the resonance Raman spectrum that act as markers for the different moieties. The $1599 \mathrm{~cm}^{-1}$ band is carbazole based; the $1549 \mathrm{~cm}^{-1}$ band is porphyrin based.

In contrast, the modes enhanced with excitation at 407 and $413 \mathrm{~nm}$ are porphyrin based. Several are observed at 1003, 1073, 1233,1356 and $1549 \mathrm{~cm}^{-1}$; that at $1549 \mathrm{~cm}^{-1}$ is shown in Figure 5.

Table 2. Experimental and calculated electronic absorption data for CZP1.

\section{Experimental}

\begin{tabular}{|c|c|c|c|c|c|c|c|c|}
\hline \multirow{2}{*}{$\begin{array}{l}\lambda / \\
\mathrm{nm}\end{array}$} & \multirow{2}{*}{$\begin{array}{c}\varepsilon \mathrm{x} \\
10^{-5^{*}}\end{array}$} & \multirow{2}{*}{$\begin{array}{l}\lambda / \\
\mathrm{nm}\end{array}$} & \multirow{2}{*}{$\mathrm{f}$} & \multirow{2}{*}{ Configuration (Coefficient) ${ }^{\#}$} & \multicolumn{4}{|c|}{ Electron transition densities (\%) } \\
\hline & & & & & Carbazole & Porphyrin & $\mathrm{CN}-\mathrm{COOH}$ & R-group \\
\hline 590 & 0.07 & 607 & 0.17 & $\mathrm{H}-1 \rightarrow \mathrm{L}(0.22), \mathrm{H} \rightarrow \mathrm{L}(0.73)$ & $20 \rightarrow 0(-20)$ & $23 \rightarrow 72(49)$ & $0 \rightarrow 27(27)$ & $5 \rightarrow 0(-57)$ \\
\hline 550 & 0.21 & 455 & 0.3 & $\mathrm{H}-2 \rightarrow \mathrm{L}+2(0.61), \mathrm{H}-1 \rightarrow \mathrm{L}+2(0.26)$ & $30 \rightarrow 1(-29)$ & $61 \rightarrow 90(29)$ & $0 \rightarrow 9(9)$ & $9 \rightarrow 0(-9)$ \\
\hline \multirow[t]{2}{*}{425} & \multirow[t]{2}{*}{2.7} & \multirow[t]{2}{*}{398} & \multirow[t]{2}{*}{2.26} & $\mathrm{H}-3 \rightarrow \mathrm{L}+1(0.27), \mathrm{H}-2 \rightarrow \mathrm{L}+2(0.15)$ & \multirow[t]{2}{*}{$17 \rightarrow 22(5)$} & \multirow[t]{2}{*}{$53 \rightarrow 76(23)$} & \multirow[t]{2}{*}{$0 \rightarrow 2(2)$} & \multirow[t]{2}{*}{$29 \rightarrow 1(-28)$} \\
\hline & & & & $\mathrm{H}-1 \rightarrow \mathrm{L}+3(0.12), \mathrm{H} \rightarrow \mathrm{L}+3(0.33)$ & & & & \\
\hline 345 & 0.45 & 380 & 0.37 & $\mathrm{H}-3 \rightarrow \mathrm{L}+1(0.14), \mathrm{H} \rightarrow \mathrm{L}+3(0.59)$ & $21 \rightarrow 32(11)$ & $30 \rightarrow 66(36)$ & $0 \rightarrow 1(1)$ & $50 \rightarrow 1(-49)$ \\
\hline \multirow[t]{2}{*}{320} & \multirow[t]{2}{*}{0.6} & \multirow[t]{2}{*}{380} & \multirow[t]{2}{*}{0.87} & $\mathrm{H}-4 \rightarrow \mathrm{L}+1(0.17), \mathrm{H}-3 \rightarrow \mathrm{L}+2(0.39)$ & \multirow[t]{2}{*}{$24 \rightarrow 1(-23)$} & \multirow[t]{2}{*}{$68 \rightarrow 94(26)$} & \multirow[t]{2}{*}{$0 \rightarrow 5(5)$} & \multirow[t]{2}{*}{$8 \rightarrow 0(-8)$} \\
\hline & & & & $\mathrm{H}-2 \rightarrow \mathrm{L}+1(0.18), \mathrm{H}-1 \rightarrow \mathrm{L}+1(0.13)$ & & & & \\
\hline
\end{tabular}

\section{Calculated}

Notes: * unit is $\mathrm{M}^{-1} \mathrm{~cm}^{-1}$; ${ }^{\#} \mathrm{H}=\mathrm{HOMO}, \mathrm{L}=\mathrm{LUMO}$.

\section{Photovoltaic performance}

Current density-voltage $(\mathrm{J}-\mathrm{V})$ curves of dye-sensitized $\mathrm{TiO}_{2}$ solar cells comprising the porphyrin dyes and a thinner $(2.2 \pm 0.1$ $\mu \mathrm{m})$ transparent $\mathrm{TiO}_{2}$ layer are shown in Fig. 6(a). Three devices were fabricated and the averaged results are shown in Table S3. J-V curves closest to the average performance are displayed.

The short circuit current density $\left(\mathrm{J}_{\mathrm{SC}}\right)$ values of all CZPs were higher than $\mathrm{ZP1}\left(6 \mathrm{~mA} \mathrm{~cm}^{-2}\right)$, with CZP3 showing $10 \%$, while the other CZPs showing a 20\% improvement. CZP1 to CZP5 all gave higher open circuit voltage $\left(\mathrm{V}_{\text {OC }}\right)$ values (740 to 770 $\mathrm{mV})$, than ZP1 $(690 \mathrm{mV})$. Fill factors (FF) vary between 0.57 and 0.65 . Considering the reproducibility, the differences in $\mathrm{J}_{\mathrm{SC}}$ and FF among CZPs are not significant (Table SI D). Both photocurrent and photovoltage of the porphyrin dyads, on the other hand, were higher than that of ZP1, leading to an overall $30 \%$ increase in power conversion efficiency $(\eta)$.

Device performance using $12 \mu \mathrm{m}$ transparent $+5.5 \mu \mathrm{m}$ scattering layer $\mathrm{TiO}_{2}$ films are shown in Fig. 6(b). Two devices have been prepared (see Table S4), and the J-V curves of the best devices are shown. A $70 \mathrm{mV}$ to $100 \mathrm{mV}$ increase in $\mathrm{V}_{\mathrm{OC}}$ and 15 20\% increase in $\mathrm{J}_{\mathrm{SC}}$ for all CZPs compared to $\mathrm{ZP1}$ are observed, consistent with the thin $\mathrm{TiO}_{2}$ photoanode results above. In this experiment, CZP1 and CZP2 show the highest performance of more than 6\% PCE, while CZP3 to CZP5 show efficiencies of $5.5 \%$. 

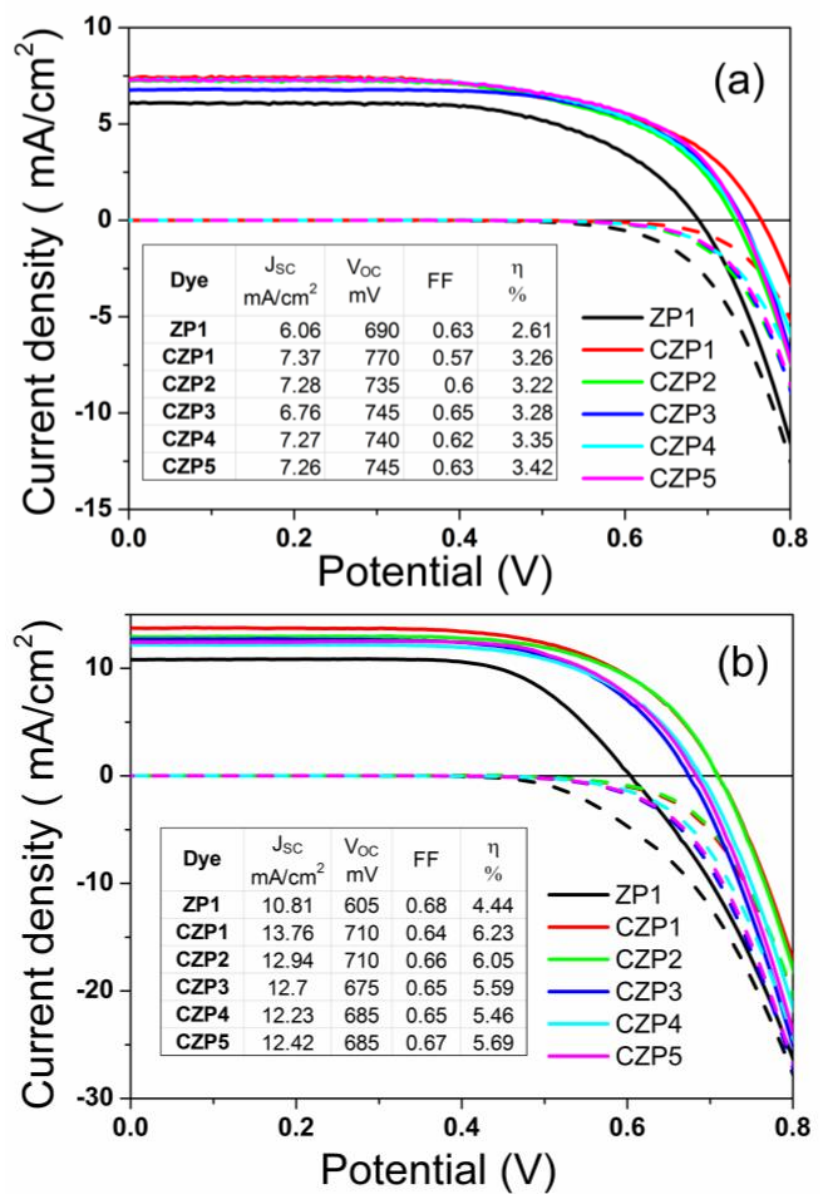

Figure 6. Current density-voltage (J-V) curves of DSSCs with the porphyrin dyes fabricated using (a) thin films: $2.2 \pm 0.1 \mu \mathrm{m}$, and (b) thick films: $12 \mu \mathrm{m}$ transparent $+5.5 \mu \mathrm{m}$ scattering $\mathrm{TiO}_{2}$, under $\mathrm{AM} 1.5$ illumination (solid lines) and in the dark (dashed lines). The inset shows the photovoltaic performance for each device.

\section{Electron transport, recombination and diffusion length}

Electron transport and recombination were investigated using electron lifetime $(\tau)$ / diffusion coefficient (D) measurements using the stepped light-induced measurements of photocurrent and photovoltage (SLIM-PCV) technique (Fig. 7). All CZPs showed higher electron lifetimes than ZP1 under the same $\mathrm{J}_{\mathrm{SC}}$ (Fig. 7(a)) or electron density (ED) (Fig. 7(b)). For example, at $1.6 \times 10^{18} \mathrm{~cm}^{-3}$, CZPs achieved lifetimes more than three times longer than ZP1. Meanwhile, less than 50\% difference was found in $\mathrm{D}$ for all the dyes as shown in Fig. 7(c), indicating that the longer $\tau$ is not caused by faster transport in the $\mathrm{TiO}_{2}$ photoanode.

Fig. 7(d) shows the relation between $\mathrm{V}_{\mathrm{OC}}$ and $\log \mathrm{ED}$, which indicates no significant (within the measurement error of the charge extraction setup) change neither in the $y$-axis intercept nor in the slope of the plot.
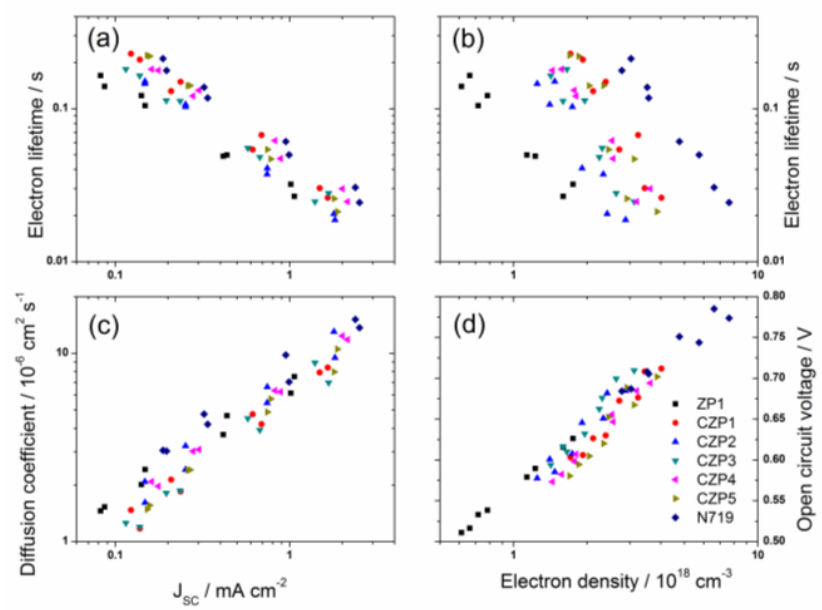
Figure 7. (a) Electron lifetime and (c) diffusion coefficient versus short circuit current density, (b) electron lifetime and (d) open circuit voltage versus electron density for the six porphyrin dyes and N719 (two samples for each dye)

Electron diffusion length (L) has been calculated using SLIM-PCV performed on DSSC using ZP1 and CZP5 dyes and using $3 \mu \mathrm{m}$ photoanode thicknesses as shown in Figure 8. The calculated $\mathrm{L}$ for both dyes decreases as the electron density increases at short circuit (ED_sc). Charge collection efficiency $\left(\mathrm{E}_{\text {coll }}\right)$ calculated using equation 3 at the shortest diffusion length was above $95 \%$ for each dye. ${ }^{54,55}$

where $\omega$ is the thickness of the $\mathrm{TiO}_{2}$ film.

$$
E_{\text {coll }}=\tanh (\omega / L) /(\omega / L)
$$

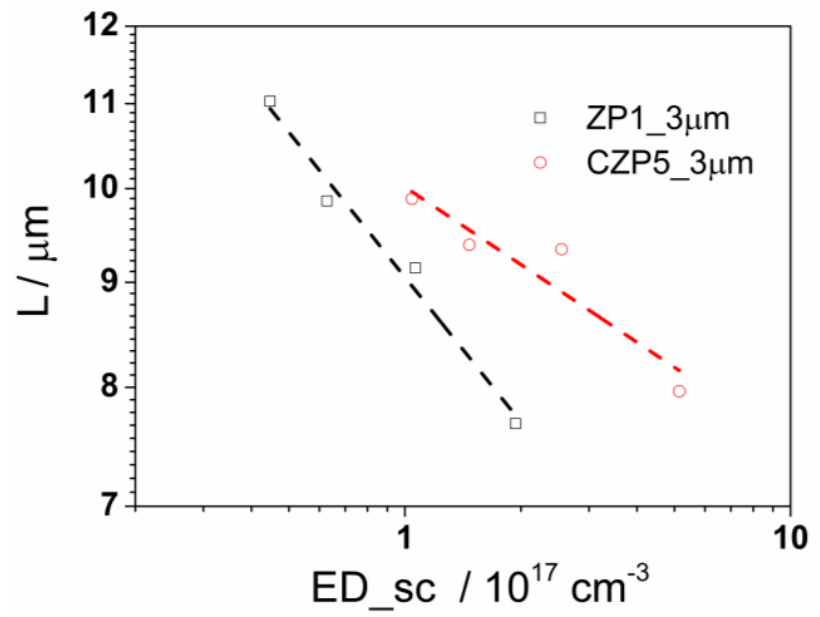

Figure 8. Diffusion length (L) versus electron density at short circuit (ED_sc) of ZP1 and CZP5 using $3 \mu \mathrm{m} \mathrm{TiO}_{2}$ films.

\section{Incident photon-to-current conversion efficiency}

Incident photon-to-current conversion efficiency (IPCE), in tandem with light harvesting efficiency (LHE) and absorbed photon-to-current conversion efficiency (APCE) measurements are shown in Fig. 9.

The IPCE of all CZPs has increased at all wavelengths compared to ZP1, with smaller differences observed within the CZPs themselves (Fig. 9(a)). The LHE maximum is nearly identical for all dyes in the Soret band and varies slightly in the Q bands. Most of the difference in LHE arises from a red-shifted and broadened Soret band for CZPs, consistent with the UVvis absorption spectra in solution. The LHE of ZP1 at Q bands is slightly lower compared to CZPs, which is consistent with its slightly lower extinction coefficient measured in solution.

The APCE of CZPs at the maximum of the Soret band was close to $100 \%$ and 10-15\% higher than that of ZP1. The averaged value of APCE of CZPs in the Q bands was 75\%, which is 15\% higher than that of ZP1 (60\%). The "gap" between the Soret and the Q bands also showed increased APCEs for CZPs compared to ZP1. We note that the APCE "peaks" within the Q band appear due to slight wavelength shifts between the LHE and IPCE spectra, which can be due to the different spectral bandwidth of these two measurements as well as any shifts in the UV-vis absorption of dye-sensitized films compared to light absorption in a fully assembled device.

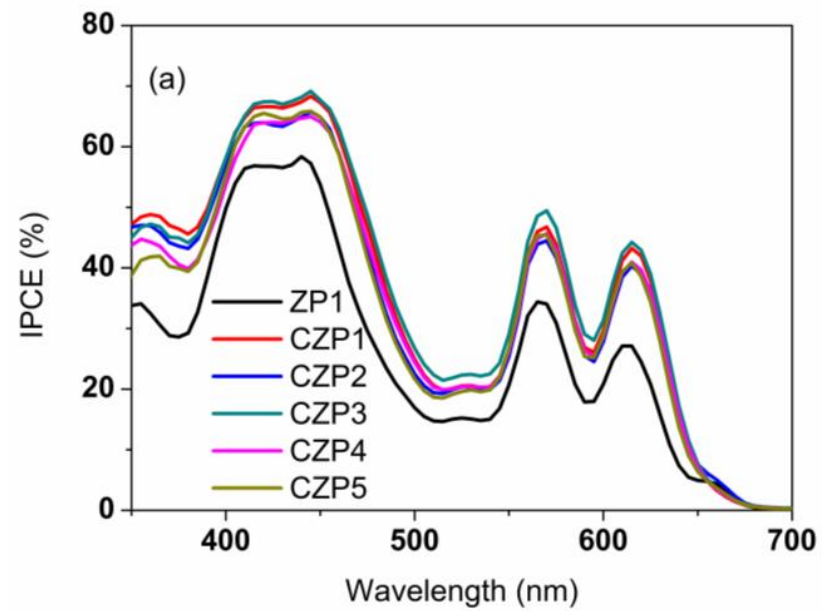



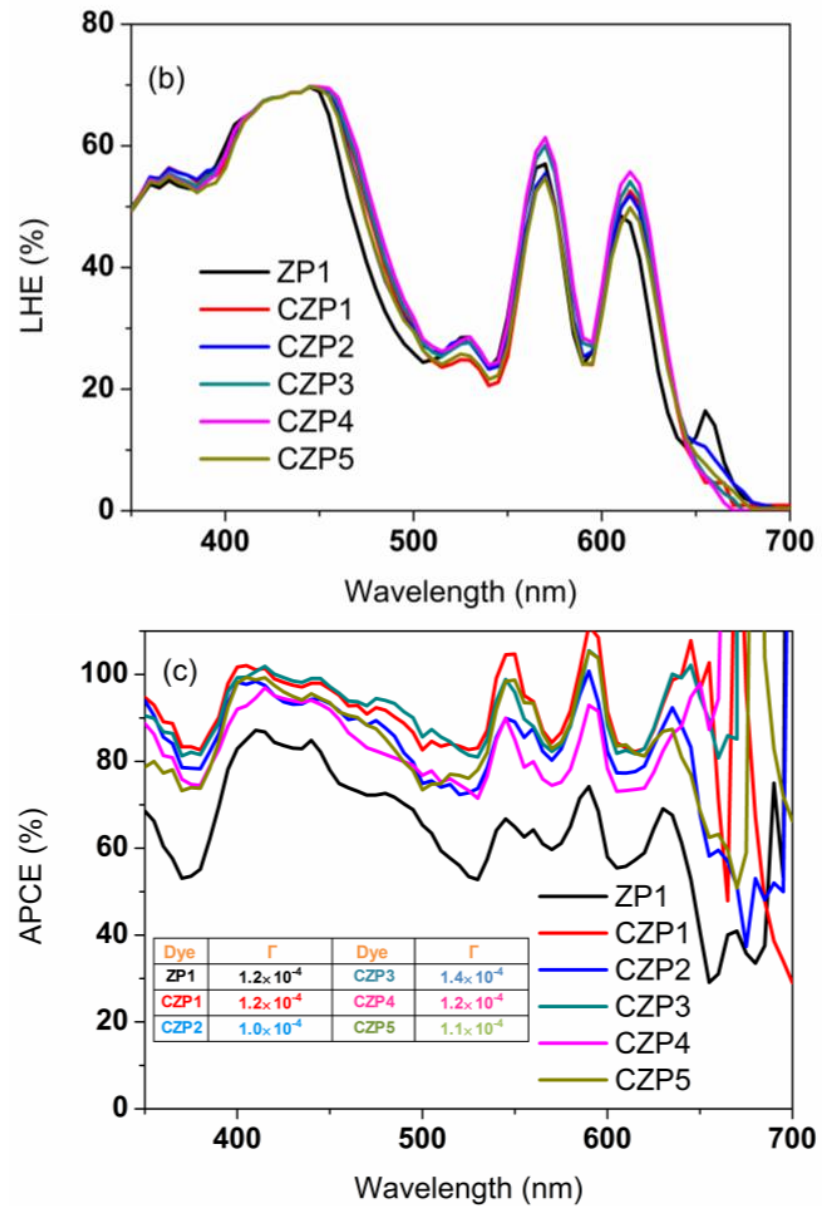

Figure 9. (a) IPCE, (b) LHE and (c) APCE spectra of porphyrin dyes on thin $\mathrm{TiO}_{2}$ films. The inset shows the dye loading. Film thickness: $2.0 \pm 0.1 \mu \mathrm{m}$; dye concentration: $0.2 \mathrm{mM}$ in THF; the unit of dye loading $(\Gamma)$ is $\mathrm{mol} \mathrm{cm}^{-3}$.

IPCE measurements were also performed on devices prepared by using chenodeoxycholic acid (CDCA) as co-adsorber, shown by the black and red curves in Figure 10 for ZP1 and CZP3, respectively. The photovoltaic data of these DSSCs are shown in Table S5. We note that the solvent was changed to ethanol (CDCA in THF resulted in lower DSSC performance for our sensitizers, see also in Table S5). Contrary to Figure 9, the peak IPCE in the Soret band (72\%) was the same for both dyes, corresponding to close to 100\% APCE (Figure 10(c)) using CDCA. Higher IPCE values were recorded for CZP3 compared to ZP1 ( 45\% vs. 33\%, averaged between $540 \mathrm{~nm}$ and $650 \mathrm{~nm}$ ) in the Q bands, corresponding to nearly $100 \%$ APCE.

ZP1 with CDCA showed lower LHE in the Q bands compared to CZP3 (Fig. 10(b) 43\% and 48\%, respectively) due to lower dye loading. ZP1 with CDCA showed only $~ 70 \%$ of the full-coverage $\left(1.2 \times 10^{-4} \mathrm{~mol} \mathrm{~cm}^{-3}\right.$ in either THF or ethanol without CDCA, see Table S5), while the amount of CZP3 with and without CDCA did not differ significantly.

The APCE for ZP1 for all wavelength ranges has increased significantly using CDCA, however, it is still lower than $100 \%$ in the Q bands. 

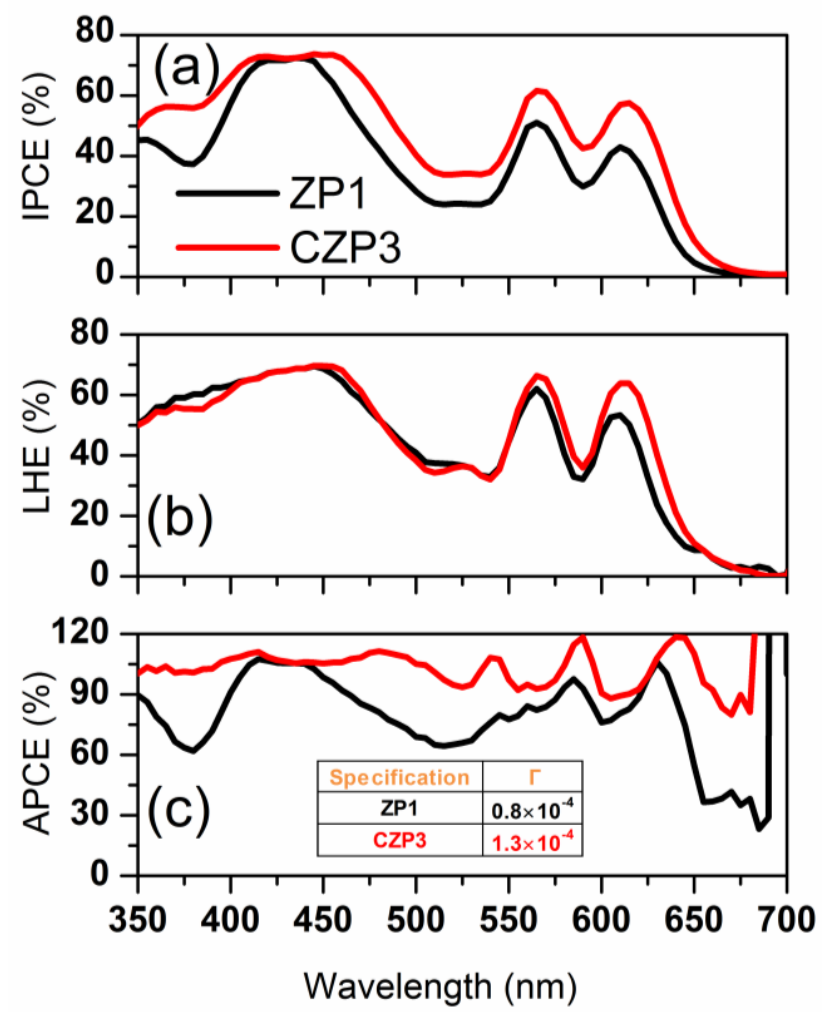

Figure 10. IPCE-LHE-APCE spectra of two dyes with CDCA in dye solution. Solvent: ethanol; film thickness: $2.7 \pm 0.1 \mu \mathrm{m}$; CDCA concentration: $2 \mathrm{mM}$; the unit of $\Gamma$ is $\mathrm{mol} \mathrm{cm}^{-3}$.

\section{Discussion}

I. Non-interacting nature of carbazole substituted di-chromophoric porphyrin dyes

The di-chromophoric dyes investigated here were chosen based on two criteria: a) the photon absorption spectrum in the visible range of the new chromophores should not have a significant overlap with the porphyrin absorption; and b) the new chromophores should not significantly interact or electronically couple with the porphyrin in the ground state. To achieve the first criterion, we used a carbazole group. To achieve the second, we introduced a non-planar structure using a nonconjugated linker.

TD-DFT calculations predicted significant orbital mixing between carbazole and porphyrin orbitals. TD-DFT, however, is known to overestimate the effect of conjugation and charge transfer in some systems ${ }^{56,57}$ and hence it is prudent to check the nature of transitions experimentally. This is achieved here through the use of resonance Raman spectroscopy, which allows the probing of electronic transitions by tuning the exciting laser wavelength to coincide with the energy of the transition. Under these conditions the Raman modes that show the greatest intensity (with enhancements of as much as $\left.10^{6}\right)^{58}$ are those that mimic the structural changes upon excitation. ${ }^{36,43,59-61}$ Because of excessive fluorescence only the electronic transitions at $\sim 420 \mathrm{~nm}$ and $\sim 350 \mathrm{~nm}$ could be investigated. The pattern of enhancement shown in Figure 4 and 5 and the similarity among the CZPs indicates that there is little conjugation in these systems and the electronic transitions that are observed are simply porphyrin based or carbazole based $\pi-\pi^{*}$ transitions; this is in contrast to the TD-DFT results however there is precedent in the literature for the overestimation of conjugation. ${ }^{57}$

Light absorption by the carbazole chromophore contributes to light harvesting at wavelengths $<370 \mathrm{~nm}$. No new bands or absorption features have been observed for CZPs, which appears to be a superposition of the porphyrin and carabzole absorption bands. The small $(<20 \%)$ decrease in $\varepsilon$ maximum of CZPs compared to ZP1, the negligible shift in $\varepsilon$ maximum wavelength at the Soret band and the small increase in the absorption intensity of CZPs in the Q band region are all consistent with the effect of geometric distortion of the porphyrin core, rather than electronic coupling between the carbazole and porphyrin. ${ }^{62-64}$

A further indication of the lack of strong coupling comes from the absence of any significant variation in the UV-vis absorption spectra by changing the electron withdrawing / donating substituents in CZP1 to CZP5. The $10 \mathrm{~nm}$ broadening of the Soret band of CZPs compared to ZP1 is independent of the substituent. Such a non-specific broadening indicates that this electronic effect largely originates from a distortion of the porphyrin core by a substituent, rather than electronic coupling between the two units. Contrary to this observation, strong electronic coupling between the substituents and the porphyrin core typically cause red-shifted or even split Soret band. ${ }^{18,65-69}$

A solvent effect of the UV-vis absorption spectrum was observed for the dyes, which can be attributed to the difference in the equilibrium solvation energies of the chromophores by changing the dielectric constant of the solvent (DCM 9.1 and DMF 38). Differences in equilibrium solvated geometries can lead to small changes in the UV-vis absorption spectra, leading to moderate changes in the oscillator strength. ${ }^{70,71}$ 
The lack of significant electronic coupling between the two chromophores is also evident from DPV measurements, showing that the first reduction and oxidation potentials assigned to one electron oxidation and reduction of the porphyrin core are not affected by the addition of carbazole units. In strongly coupled $\pi$-conjugated systems, a noticible change is expected. ${ }^{16,69,72}$

\section{Origin of DSSC performance improvement}

An electrochemical energy diagram constructed using data from Figure 2 (Table S2, Figure S1A) suggests that the first oxidation / reduction potentials $\left(\mathrm{E}_{\mathrm{Ox}}{ }^{1 \mathrm{st}}\right.$ and $\mathrm{E}_{\mathrm{Re}}{ }^{1 \mathrm{st}}$ ), mainly responsible for performance determing electron transfer steps, have not changed significantly between CZPs and ZP1. A similar energy level diagram is constructed from the TD-DFT calculations, shown in Figure S1B. It shows similar energies for the frontier MOs as those calculated from electrochemical measurements, except for CZP1, for which lowering of the HOMO by the carbazole is predicted by TD-DFT. As explained above, this may originate from the overestimation of the extent of electronic coupling between the carbazole moiety and the porphyrin core.

The kinetics of electron injection is influenced by the density of available acceptor states at the electrochemical energy of the first excited state of the sensitizing dye, approximated by the first reduction potential. ${ }^{73}$ Note that the conduction band edge potential $\left(\mathrm{E}_{\mathrm{CB}}\right)$ of $\mathrm{TiO}_{2}$ in operational solar cells was also found to be nearly identical (Fig. 7(d)), suggesting that modifications to the dye structure did not change the adsorption / desorption of electrolyte components nor the strength of dipole interactions on the $\mathrm{TiO}_{2}$ surface. Since the mean energy difference between $\mathrm{E}_{\mathrm{Re}}{ }^{1 \mathrm{st}}$ and $\mathrm{E}_{\mathrm{CB}}$ is similar among the dyes examined here, any change in electron injection efficiency must come from some local variations in the $\mathrm{TiO}_{2} /$ dye interaction, brought about by variations in dye/ $\mathrm{TiO}_{2}$ arrangement. ${ }^{74,75}$

The driving force for dye regeneration approximated by the electrochemical potential difference between the redox mediator $\left(\mathrm{E}_{\mathrm{ele}}\right)$ and the dye/dye ${ }^{+}$in solution $\left(\mathrm{E}_{\mathrm{Ox}}{ }^{1 \mathrm{st}}\right)$ is also quite similar, therefore it cannot explain the observed differences in DSSC performance. Comparing with the carbazole-TPA redox reactions (Cb1), the CZP1 DPV plots can be explained by overlapping one-electron oxidations of the porphyrin core and the carbazole-TPA units. The $\mathrm{E}_{\mathrm{Ox}}{ }^{2 \text { nd }}$ of CZP1 is consistent with superimposed second oxidation reactions of the porphyrin core and the carbazole-TPA unit.

For the other CZPs, the $\mathrm{E}_{\mathrm{Ox}}{ }^{1 \mathrm{st}}$ is attributed to porphyrin oxidation, which corresponds to the lowest oxidation potential within the dyads. The $\mathrm{E}_{\mathrm{Ox}}{ }^{\text {2nd }}\left(\mathrm{E}_{\mathrm{Ox}}{ }^{\text {3rd }}\right)$ of CZPs shifted slightly negatively (positively) compared to the $\mathrm{E}_{\mathrm{Ox}}{ }^{2 \text { nd }}$ of the porphyrin in ZP1. We suggest that this arises from splitting of the electronic levels of the singly-oxidised porphyrin by the carbazole substituent to two arrangements with a delocalized (negative shift) and localized cation radical (positive shift), the latter having a stronger coulomb energy. While the exact nature of these two configurations is not clear, spectro-electrochemical data (not shown here) confirms the assignment of the above $\mathrm{E}_{\mathrm{Ox}}{ }^{2 \text { nd }}\left(\mathrm{E}_{\mathrm{Ox}}{ }^{3 \mathrm{rd}}\right)$ oxidation bands to having both porphyrin and carbazole substituent characters.

The $\mathrm{E}_{\mathrm{Ox}}{ }^{\text {th }}$ at $+0.8 \mathrm{~V}$ vs Fc/Fc ${ }^{+}$for CZP2 and $\mathrm{CZP} 5$, and at $+0.95 \mathrm{vs} \mathrm{Fc} / \mathrm{Fc}^{+}$for $\mathrm{CZP} 4$ corresponds to the oxidation of the carbazole side chain, and shows the effect of carbazole substitution. CZP2 and CZP5 with $\mathrm{CF}_{3}$ units in the para or meso positions show similar $\mathrm{E}_{\mathrm{Ox}}{ }^{\text {th }}$ values, while CZP3 and CZP4 with methyl and methoxy groups are harder to oxidise.

The increased electron lifetime of the carbazole-substituted porphyrins is consistent with a steric blocking effect of the bulkier CZPs, which prevents the build-up of the oxidised species in the electrolyte near the $\mathrm{TiO}_{2}$ interface. ${ }^{21,76}$ Not only the long alkyl chain attached to the carbazole unit, but also the non-planar structure of the di-chromophoric dyes could contribute to this blocking effect. The relative position of $\mathrm{E}_{\mathrm{CB}}$ obtained from the charge extraction results shown in Fig. 7(d) suggest no significant change in the relative $\mathrm{E}_{\mathrm{CB}}$ positions (the $y$-axis intercept) nor in the slope of $V_{O C} v s \log (E D)$. This indicates that the Density of States (DOS) distribution of trap states in $\mathrm{TiO}_{2}$ near the Fermi level did not change.

As a consequence of the increased electron lifetime, no significant shift in $\mathrm{E}_{\mathrm{CB}}$ and higher $\mathrm{J}_{\mathrm{SC}}$ (Fig. 6), the electron density and the $\mathrm{V}_{\mathrm{OC}}$ of CZPs is increased. CZP1 with $\sim 2.2 \mu \mathrm{m} \mathrm{TiO}$ films achieved nearly the same $\mathrm{V}_{\mathrm{OC}}(770 \mathrm{mV})$ as N719 (Table S3), which is one of the highest among porphyrin dyads using the iodine/triiodide redox couple. The electron lifetime of this dye is among the longest reported for porphyrin sensitized solar cells and reaches half the value of N719-sensitized cells at the same electron density. Since dye uptake did not vary significantly between the porphyrin compounds (Table S3), the closer packing of carbazole-substituted porphyrins reduced the concentration of electron accepting electrolyte species near the $\mathrm{TiO}_{2}$ interface. Due to the non-conjugated di-chromophoric arrangement of the carbazole to the porphyrin, dispersion forces did not counteract the blocking effect, leading to an overall improvement in electron lifetime.

The calculated diffusion lengths were two to three times longer than the $\mathrm{TiO}_{2}$ film thickness used for DSSC fabrication in Figure $6(2.2 \mu \mathrm{m})$, therefore the differences in $\mathrm{J}_{\mathrm{SC}}$ cannot be attributed to improved charge collection. To confirm the calculated high efficiency of charge collection $(>95 \%$, Fig. 8), IPCE measurements by illuminating through the hole collector Pt counter electrode side were performed (not shown). No difference between front and back illumination IPCE values has been observed for the $\mathrm{Q}$ bands. Measurements for the Soret band illumination were inconclusive due to overlapping electrolyte absorption with the high intensity Soret band absorption. Using thick (12 $\mu \mathrm{m}$ transparent $+5.5 \mu \mathrm{m}$ scattering) $\mathrm{TiO}_{2}$ photoanodes (Fig. 6(b)) may lead to some collection losses that contribute to the lower $\mathrm{J}_{\mathrm{SC}}$ of ZP1-sensitized solar cells.

\section{Origin of the increased IPCE}

CZPs achieved $\sim 20 \%$ higher $\mathrm{J}_{\mathrm{SC}}$ than ZP1 as illustrated in Fig. 6, which have contributions from both increased light harvesting (due to moderate carbazole absorption, broadened Soret band and enhanced Q band absorption of the non-planar carbazole substituted porphyrin) and increased APCE as shown in Figure 9.

A new absorption band at $\sim 660 \mathrm{~nm}$ is observed for $\mathrm{ZP1}$ on $\mathrm{TiO}_{2}$ (Fig. 9(b)), which is assigned to light absorption by aggregated $\mathrm{ZP} 1$ molecules on the $\mathrm{TiO}_{2}$ surface. UV-vis absorption spectra of high concentration $(30 \mu \mathrm{M})$ dye solutions were measured (Figure S3). ZP1 showed a clear absorbance feature at $650 \mathrm{~nm}$ with $\varepsilon$ of $1200 \sim 1300 \mathrm{M}^{-1} \mathrm{~cm}^{-1}$ in THF, while this feature was not observed when CDCA was used as co-adsorber in ethanol, suggesting that ZP1 aggregates may form in concentrated dye solutions and bind to the $\mathrm{TiO}_{2}$ with their structure maintained. On the contrary, we did not find any indication of aggregation by CZPs in either THF or adsorbed to $\mathrm{TiO}_{2}$. This may be related to the introduction of the bulky 
carbazole chromophores with alkyl side chains. Although aggregation can, for some organic dyes, lead to broadened light harvesting range, ${ }^{77,78}$ or increased injection efficiency, ${ }^{79}$ the aggregation of porphyrins has been reported to be detrimental for DSSC performance. ${ }^{24,32,68,80-82}$ The addition of CDCA to ZP1 solution dissolved in THF was not effective in removing the $650 \mathrm{~nm}$ absorption band (Fig. S3), confirming the lack of any beneficial effect of CDCA using THF as a solvent (Table S5).

The more closely packed dye monolayer and the lack of aggregation not only improves electron lifetime through a blocking effect, but also increases charge injection efficiency by eliminating alternative excited state relaxation pathways available in dye aggregates. ${ }^{24,83,84}$ Our previous work suggested that the presence of non-injecting, ineffective porphyrin dyes limits charge injection efficiency. ${ }^{85}$ Porphyrin dyes with strong electron coupling to $\mathrm{TiO}_{2}$ inject electron on the femtosecond timescale. ${ }^{22,66}$ However, a fraction of dye molecules, which are aggregated or only weakly attached, do not participate in electron injection, but instead undergo radiative or non-radiative exited state decay to the ground state. ${ }^{86,87}$ Femtosecond electron injection studies on the P199 porphyrin dye, nearly identical to ZP1 having a 4-methylphenyl group instead of the 2,4,6-trimethylphenyl of ZP1, showed femtosecond electron injection, yet only $\sim 0.7$ quantum yield of charge injection, suggesting that the presence of a similar non-injecting, aggregated dye layer contributes to lower APCE values. ${ }^{20}$

All the investigated porphyrins showed 15 20\% lower APCE in the Q band compared to that of the Soret band (Fig. 9(c)). This can be attributed either to wavelength dependent charge injection efficiency or charge collection efficiency. ${ }^{54}{ }^{88}$ The former would arise if electron injection is more efficient from higher lying excited states within the Soret band due to, for example, the larger density of excited states at this dye excited state energy or increased electronic coupling between the dye excited state and $\mathrm{TiO}_{2}$. The calculated collection efficiency measured in the $\mathrm{Q}$ band was at least $95 \%$. Based on this, the lower APCE in the Q bands cannot be attributed to collection losses. We note, however, that IPCE measurements were typically performed at lower light intensity compared to SLIM-PCV. It has been reported that the IPCE only weakly depends on the light intensity ${ }^{89}$ however, others argue that an electron density that is too high or too low in $\mathrm{TiO}_{2}$ would both decrease IPCE. ${ }^{90}$ Some non-linearity of the photocurrent at the very low light intensity range $\left(0.07\right.$ to $\left.0.2 \mathrm{~mW} \mathrm{~cm}^{-2}\right)$ has been observed (Figure S4). However, similar non-linearity was observed for both CZP5 and ZP1 in the Soret and Q bands suggesting that collection losses cannot explain the differences in APCE values for these dyes.

The use of CDCA co-adsorber provides similar APCE improvements compared to carbazole substitution for ZP1. The APCE in the Soret band reached close to $100 \%$ and nearly around $80 \%$ in the Q-band, which is similar to CZPs without CDCA. The absorption feature at $660 \mathrm{~nm}$ on $\mathrm{TiO}_{2}$ is not present when CDCA is used, suggesting that dye aggregation has been reduced for ZP1 in this case. However, the use of CDCA resulted in lower dye loading, which led to lower LHE and IPCE.

The use of CDCA for CZP3 leads to a more modest, approximately 5\% increase in APCE across the entire wavelength, which is close to the accuracy of the APCE measurement technique employed. These results suggest that the main limitation to APCE losses arise from the presence of non-injecting dyes, which can be minimised using bulky carbazole substituents or by using a co-adsorber.

We note that from a photovoltaic performance point of view, functionalization by carbazole units appears to be more favourable as it provides a simultaneous increase in $\mathrm{J}_{\mathrm{SC}}$ and $\mathrm{V}_{\mathrm{OC}}$ (see Table S5).

Using CZP1 and CZP3 as examples, increase in the photocurrent of porphyrin dyads compared to ZP1 is quantitatively analysed by discussing the $\mathrm{J}_{\mathrm{SC}}$ improvement $\left(\Delta \mathrm{J}_{\mathrm{SC}}\right)$ due to three different factors: i) overall increased APCE; ii) increased LHE due to Soret band broadening; and iii) enhanced APCE in $315 \mathrm{~nm}$ to $380 \mathrm{~nm}$, where the carbazole chromophore absorbs (see Table S6). The first two effects can be assigned to a structural, steric effect influencing charge injection / recombination kinetics as well as broadened absorption by the porphyrin core, while the latter one is a more specific chromophore effect. It is noted that below $380 \mathrm{~nm}, \mathrm{TiO}_{2}$, electrolyte components, porphyrin dye and carbazole side chain all absorb to some extent, so quantifying the chromophores effect alone is experimentally challenging. Nevertheless, by integrating the photocurrent from IPCE curve in the regions $315-380 \mathrm{~nm}, 385-440 \mathrm{~nm}, 445-510 \mathrm{~nm}$ and $545-700 \mathrm{~nm}$, the upper limit of the chromophore effect can be estimated to be less than 10\%. The broadening of the Soret band (385-440 $\mathrm{nm})$ contributes to around $30 \%$ improvement, while the remaining is due to the overall APCE improvement.

\section{Conclusions}

The origin of simultaneous improvement to photocurrent and photovoltage in a series of carbazole-substituted dichromophoric dyes used as sensitizers in dye-sensitized solar cells was investigated. UV-vis absorption, resonance Raman spectroscopy and differential pulse voltammetry results indicate no significant interaction between the carbazole unit and the porphyrin core, in contrast to TD-DFT calculations, which overestimated the effect of the conjugation between those components. Attaching bulky carbazole units also has the benefit of increased photovoltage by increasing the electron lifetime due to a steric blocking effect, while simultaneously increasing the $\mathrm{J}_{\mathrm{SC}}$ by enhanced light harvesting and electron injection efficiencies. The enhanced light harvesting primarily originates from a broadened Soret band absorption of the nonplanar porphyrin chromophore. The increased electron injection efficiency derived from APCE measurements suggests the elimination of non-electron injecting dyes, by supressing dye aggregation and/or eliminating weakly-bound dye molecules. The di-chromophoric approach using bulky substituents without significant electronic coupling to the main porphyrin chromophore is suggested to be a viable alternative to using CDCA co-adsorber providing a simultaneous increase to $\mathrm{J}_{\mathrm{SC}}$ and $\mathrm{V}_{\mathrm{OC}}$, leading to DSSC performance exceeding $6 \%$ when thick $\mathrm{TiO}_{2}$ photoanodes are applied.

\section{Acknowledgement:}

AJM, KCG, PW, SM and TMC acknowledge support from the Australian Research Council (ARC) through Discovery Project no. DP110102201 and ARC Centre of Excellence for Electromaterials Science. AJM acknowledges funding for 
Australian Research Fellowship (ARF). AJM, PW acknowledges support from ANFF. ABSE and KCG acknowledge the University of Otago and the MacDiarmid Institute for Advanced materials and Nanotechnology for funding.

Notes

a ARC Centre of Excellence for Electromaterials Science, Intelligent Polymer Research Institute, University of Wollongong, Wollongong, NSW 2522, Australia. Email: attila@uow.edu.au; Tel: +61242981429

${ }^{b}$ MacDiarmid Institute for Advanced Materials and Nanotechnology, Department of Chemistry, University of Otago, Dunedin, New Zealand.

${ }^{c}$ Division of Chemistry and Materials, Faculty of Textile Science and Technology, Shinshu University, Ueda, Nagano 386-8567, Japan.

$\dagger$ Electronic Supplementary Information (ESI) available: [Material synthesis, UV-vis absorption oscillator strength, Electrochemical properties, Energy diagram, Detailed solar cell characterisation, UV-vis absorption of concentrated dye solutions, $\mathrm{J}_{\mathrm{sc}}$ dependence on light intensity, Quantification of increased $\mathrm{J}_{\mathrm{sc}}$. See DOI: 10.1039/b000000x/

1. A. Hagfeldt, G. Boschloo, L. Sun, L. Kloo and H. Pettersson, Chem. Rev., 2010, 110, 65956663.

2. A. Mishra, M. K. R. Fischer and P. Bäuerle, Angew. Chem. Int. Ed., 2009, 48, 2474-2499.

3. A. J. Mozer, P. Wagner, D. L. Officer, G. G. Wallace, W. M. Campbell, M. Miyashita, K. Sunahara and S. Mori, Chem. Commun., 2008, 0, 4741-4743.

4. J. Bisquert, F. Fabregat-Santiago, I. n. Mora-Serol], G. Garcia-Belmonte and S. Gimei!?nez, J. Phys. Chem. C, 2009, 113, 17278-17290.

5. T. Marinado, K. Nonomura, J. Nissfolk, M. K. Karlsson, D. P. Hagberg, L. Sun, S. Mori and A. Hagfeldt, Langmuir, 2009, 26, 2592-2598.

6. J. R. Darwent, P. Douglas, A. Harriman, G. Porter and M.-C. Richoux, Coord. Chem. Rev. $1982,44,83-126$.

7. L.-L. Li and E. W.-G. Diau, Chem. Soc. Rev., 2013, 42, 291-304.

8. W. M. Campbell, A. K. Burrell, D. L. Officer and K. W. Jolley, Coord. Chem. Rev., 2004, 248, 1363-1379.

9. S. Eu, S. Hayashi, T. Umeyama, A. Oguro, M. Kawasaki, N. Kadota, Y. Matano and H. Imahori, J. Phys. Chem. C, 2007, 111, 3528-3537.

10. M. Tanaka, S. Hayashi, S. Eu, T. Umeyama, Y. Matano and H. Imahori, Chem. Commun., 2007, 2069-2071.

11. S. Hayashi, M. Tanaka, H. Hayashi, S. Eu, T. Umeyama, Y. Matano, Y. Araki and H. Imahori, J. Phys. Chem. C, 2008, 112, 15576-15585.

12. S. Eu, S. Hayashi, T. Umeyama, Y. Matano, Y. Araki and H. Imahori, J. Phys. Chem. C, 2008, 112, 4396-4405.

13. H. Imahori, S. Hayashi, H. Hayashi, A. Oguro, S. Eu, T. Umeyama and Y. Matano, J. Phys. Chem. C, 2009, 113, 18406-18413.

14. C.-P. Hsieh, H.-P. Lu, C.-L. Chiu, C.-W. Lee, S.-H. Chuang, C.-L. Mai, W.-N. Yen, S.-J. Hsu, E. W.G. Diau and C.-Y. Yeh, J. Mater. Chem., 2009, 20, 1127-1134.

15. T. Bessho, S. M. Zakeeruddin, C. Y. Yeh, E. W. G. Diau and M. Grätzel, Angew. Chem. Int. Ed., 2010, 49, 6646-6649.

16. Y.-C. Chang, C.-L. Wang, T.-Y. Pan, S.-H. Hong, C.-M. Lan, H.-H. Kuo, C.-F. Lo, H.-Y. Hsu, C.-Y. Lin and E. W.-G. Diau, Chem. Commun., 2011, 47, 8910-8912.

17. A. Yella, H.-W. Lee, H. N. Tsao, C. Yi, A. K. Chandiran, M. K. Nazeeruddin, E. W.-G. Diau, C.-Y. Yeh, S. M. Zakeeruddin and M. Grätzel, Science, 2011, 334, 629-634.

18. C.-L. Mai, W.-K. Huang, H.-P. Lu, C.-W. Lee, C.-L. Chiu, Y.-R. Liang, E. W.-G. Diau and C.-Y. Yeh, Chem. Commun., 2010, 46, 809-811.

19. C.-L. Wang, Y.-C. Chang, C.-M. Lan, C.-F. Lo, E. W.-G. Diau and C.-Y. Lin, Energy Environ. Sci., 2011, 4, 1788-1795. 
20. A. J. Mozer, M. J. Griffith, G. Tsekouras, P. Wagner, G. G. Wallace, S. Mori, K. Sunahara, M. Miyashita, J. C. Earles, K. C. Gordon, L. Du, R. Katoh, A. Furube and D. L. Officer, J. Am. Chem. Soc., 2009, 131, 15621-15623.

21. K. Sunahara, M. J. Griffith, T. Uchiyama, P. Wagner, D. L. Officer, G. G. Wallace, A. J. Mozer and S. Mori, ACS Appl. Mater. Interfaces, 2013, 5, 10824-10829.

22. M. J. Griffith, K. Sunahara, P. Wagner, K. Wagner, G. G. Wallace, D. L. Officer, A. Furube, R. Katoh, S. Mori and A. J. Mozer, Chem. Commun., 2012, 48, 4145-4162.

23. M. K. Nazeeruddin, R. Humphry-Baker, D. L. Officer, W. M. Campbell, A. K. Burrell and M. Grätzel, Langmuir, 2004, 20, 6514-6517.

24. Q. Wang, W. M. Campbell, E. E. Bonfantani, K. W. Jolley, D. L. Officer, P. J. Walsh, K. Gordon, R. Humphry-Baker, M. K. Nazeeruddin and M. Grätzel, J. Phys. Chem. B, 2005, 109, 1539715409.

25. W. M. Campbell, K. W. Jolley, P. Wagner, K. Wagner, P. J. Walsh, K. C. Gordon, L. SchmidtMende, M. K. Nazeeruddin, Q. Wang, M. Grätzel and D. L. Officer, J. Phys. Chem. C, 2007, $111,11760-11762$.

26. J. K. Park, H. R. Lee, J. Chen, H. Shinokubo, A. Osuka and D. Kim, J. Phys. Chem. C, 2008, 112, 16691-16699.

27. S. Mathew, A. Yella, P. Gao, R. Humphry-Baker, B. F. E. Curchod, N. Ashari-Astani, I. Tavernelli, U. Rothlisberger, M. K. Nazeeruddin and M. Grätzel, Nat. Chem., 2014, 6, 242247.

28. H. Imahori, J. Phys. Chem. B, 2004, 108, 6130-6143.

29. R. B. M. Koehorst, G. K. Boschloo, T. J. Savenije, A. Goossens and T. J. Schaafsma, J. Phys. Chem. B, 2000, 104, 2371-2377.

30. Y. Liu, H. Lin, J. T. Dy, K. Tamaki, J. Nakazaki, D. Nakayama, S. Uchida, T. Kubo and H. Segawa, Chem. Commun., 2011, 47, 4010-4012.

31. J. Warnan, Y. Pellegrin, E. Blart and F. Odobel, Chem. Commun., 2012, 48, 675-677.

32. C.-W. Lee, H.-P. Lu, C.-M. Lan, Y.-L. Huang, Y.-R. Liang, W.-N. Yen, Y.-C. Liu, Y.-S. Lin, E. W.-G. Diau and C.-Y. Yeh, Chem. Eur. J., 2009, 15, 1403-1412.

33. H.-P. Wu, Z.-W. Ou, T.-Y. Pan, C.-M. Lan, W.-K. Huang, H.-W. Lee, N. M. Reddy, C.-T. Chen, W.-S. Chao, C.-Y. Yeh and E. W.-G. Diau, Energy Environ. Sci., 2012, 5, 9843-9848.

34. J. K. Park, J. Chen, H. R. Lee, S. W. Park, H. Shinokubo, A. Osuka and D. Kim, J. Phys. Chem. C, 2009, 113, 21956-21963.

35. G. W. T. M. J. Frisch, H. B. Schlegel, G. E. Scuseria, , J. R. C. M. A. Robb, G. Scalmani, V. Barone, B. Mennucci, , H. N. G. A. Petersson, M. Caricato, X. Li, H. P. Hratchian, , J. B. A. F. Izmaylov, G. Zheng, J. L. Sonnenberg, M. Hada, , K. T. M. Ehara, R. Fukuda, J. Hasegawa, M. Ishida, T. Nakajima, , O. K. Y. Honda, H. Nakai, T. Vreven, J. A. Montgomery, Jr., , F. O. J. E. Peralta, M. Bearpark, J. J. Heyd, E. Brothers, , V. N. S. K. N. Kudin, R. Kobayashi, J. Normand, , A. R. K. Raghavachari, J. C. Burant, S. S. Iyengar, J. Tomasi, , N. R. M. Cossi, J. M. Millam, M. Klene, J. E. Knox, J. B. Cross, , C. A. V. Bakken, J. Jaramillo, R. Gomperts, R. E. Stratmann, , A. J. A. O. Yazyev, R. Cammi, C. Pomelli, J. W. Ochterski, , K. M. R. L. Martin, V. G. Zakrzewski, G. A. Voth, , J. J. D. P. Salvador, S. Dapprich, A. D. Daniels, , J. B. F. O. Farkas, J. V. Ortiz, J. Cioslowski, and a. D. J. Fox, in Revision A.02, Gaussian, Inc., Wallingford CT, 2009.

36. R. Horvath and K. C. Gordon, Coord. Chem. Rev., 2010, 254, 2505-2518.

37. T. M. Clarke, K. C. Gordon, D. L. Officer, S. B. Hall, G. E. Collis and A. K. Burrell, J. Phys. Chem. A, 2003, 107, 11505-11516.

38. R. Horvath, C. A. Otter, K. C. Gordon, A. M. Brodie and E. W. Ainscough, Inorg. Chem., 2010, 49, 4073-4083.

39. T. M. McLean, D. M. Cleland, S. J. Lind, K. C. Gordon, S. G. Telfer and M. R. Waterland, Chem. Asian J., 2010, 5, 2036-2046.

40. J. C. Earles, K. C. Gordon, D. L. Officer and P. Wagner, J. Phys. Chem. A, 2007, 111, 71717180. 
41. S. J. Lind, K. C. Gordon and M. R. Waterland, J. Raman Spectrosc., 2008, 39, 1556-1567.

42. M. R. Waterland, S. L. Howell and K. C. Gordon, J. Phys. Chem. A, 2007, 111, 4604-4611.

43. A. B. S. Elliott, K. C. Gordon, T. Khoury and M. J. Crossley, J. Mol. Struct., 2012, 1029, 187198.

44. J. E. M. Lewis, A. B. S. Elliott, C. J. McAdam, K. C. Gordon and J. D. Crowley, Chem. Sci., 2014, 5, 1833-1843.

45. K. Wagner, M. J. Griffith, M. James, A. J. Mozer, P. Wagner, G. Triani, D. L. Officer and G. G. Wallace, J. Phys. Chem. C, 2011, 115, 317-326.

46. W. Kubo, A. Sakamoto, T. Kitamura, Y. Wada and S. Yanagida, J. Photochem. Photobiol., A, 2004, 164, 33-39.

47. S. Nakade, T. Kanzaki, Y. Wada and S. Yanagida, Langmuir, 2005, 21, 10803-10807.

48. N. W. Duffy, L. M. Peter, R. M. G. Rajapakse and K. G. U. Wijayantha, Electrochem. Commun., 2000, 2, 658-662.

49. J. R. Jennings, F. Li and Q. Wang, J. Phys. Chem. C, 114, 14665-14674.

50. J. Villanueva-Cab, H. Wang, G. Oskam and L. M. Peter, J. Phys. Chem. Lett., 2010, 1, 748-751.

51. P. R. F. Barnes and B. C. O'Regan, J. Phys. Chem. C, 114, 19134-19140.

52. J. F. Ambrose and R. F. Nelson, J. Electrochem. Soc., 1968, 115, 1159-1164.

53. E. T. Seo, R. F. Nelson, J. M. Fritsch, L. S. Marcoux, D. W. Leedy and R. N. Adams, J. Am. Chem. Soc., 1966, 88, 3498-3503.

54. J. Halme, G. Boschloo, A. Hagfeldt and P. Lund, J. Phys. Chem. C, 2008, 112, 5623-5637.

55. P. R. F. Barnes, K. Miettunen, X. Li, A. Y. Anderson, T. Bessho, M. Grätzel and B. C. O'Regan, Adv. Mater., 2013, 25, 1881-1922.

56. A. Dreuw and M. Head-Gordon, J. Am. Chem. Soc., 2004, 126, 4007-4016.

57. Z. L. Cai, K. Sendt and J. R. Reimers, J. Chem. Phys., 2002, 117, 5543-5549.

58. R. J. H. Clark and T. J. Dines, Angew. Chem. Int. Ed., 1986, 25, 131-158.

59. A. Y. Hirakawa and M. Tsuboi, Science, 1975, 188, 359-361.

60. J. C. Earles, K. C. Gordon, A. W. I. Stephenson, A. C. Partridge and D. L. Officer, PCCP, 2011, 13, 1597-1605.

61. S. J. Lind, K. C. Gordon, S. Gambhir and D. L. Officer, PCCP, 2009, 11, 5598-5607.

62. O. Cramariuc, T. I. Hukka and T. T. Rantala, Chem. Phys., 2004, 305, 13-26.

63. D. Kim and A. Osuka, Acc. Chem. Res., 2004, 37, 735-745.

64. H. S. Cho, N. W. Song, Y. H. Kim, S. C. Jeoung, S. Hahn, D. Kim, S. K. Kim, N. Yoshida and A. Osuka, J. Phys. Chem. A, 2000, 104, 3287-3298.

65. P. J. Angiolillo, V. S. Y. Lin, J. M. Vanderkooi and M. J. Therien, J. Am. Chem. Soc., 1995, 117, 12514-12527.

66. C.-Y. Lin, C.-F. Lo, L. Luo, H.-P. Lu, C.-S. Hung and E. W.-G. Diau, J. Phys. Chem. C, 2009, 113, 755-764.

67. C.-F. Lo, S.-J. Hsu, C.-L. Wang, Y.-H. Cheng, H.-P. Lu, E. W.-G. Diau and C.-Y. Lin, J. Phys. Chem. C, 2010, 114, 12018-12023.

68. H.-P. Lu, C.-Y. Tsai, W.-N. Yen, C.-P. Hsieh, C.-W. Lee, C.-Y. Yeh and E. W.-G. Diau, J. Phys. Chem. C, 2009, 113, 20990-20997.

69. C.-P. Hsieh, H.-P. Lu, C.-L. Chiu, C.-W. Lee, S.-H. Chuang, C.-L. Mai, W.-N. Yen, S.-J. Hsu, E. W.G. Diau and C.-Y. Yeh, J. Mater. Chem., 2010, 20, 1127-1134.

70. J. R. Weinkauf, S. W. Cooper, A. Schweiger and C. C. Wamser, J. Phys. Chem. A, 2002, 107, 3486-3496.

71. K.-F. Chen, C.-W. Chang, J.-L. Lin, Y.-C. Hsu, M.-C. P. Yeh, C.-P. Hsu and S.-S. Sun, Chem. Eur. J., 2010, 16, 12873-12882.

72. C.-L. Wang, Y.-C. Chang, C.-M. Lan, C.-F. Lo, E. Wei-Guang Diau and C.-Y. Lin, Energy Environ. Sci., 2011, 4, 1788-1795. 
73. T. D. Santos, A. Morandeira, S. Koops, A. J. Mozer, G. Tsekouras, Y. Dong, P. Wagner, G. Wallace, J. C. Earles, K. C. Gordon, D. Officer and J. R. Durrant, J. Phys. Chem. C, 2010, 114, 3276-3279.

74. R. Katoh, A. Furube, K. Hara, S. Murata, H. Sugihara, H. Arakawa and M. Tachiya, J. Phys. Chem. B, 2002, 106, 12957-12964.

75. R. Katoh, A. Furube, A. V. Barzykin, H. Arakawa and M. Tachiya, Coord. Chem. Rev., 2004, $248,1195-1213$.

76. J.-i. Nishida, T. Masuko, Y. Cui, K. Hara, H. Shibuya, M. Ihara, T. Hosoyama, R. Goto, S. Mori and Y. Yamashita, J. Phys. Chem. C, 114, 17920-17925.

77. J. R. Mann, M. K. Gannon, T. C. Fitzgibbons, M. R. Detty and D. F. Watson, J. Phys. Chem. C, 2008, 112, 13057-13061.

78. A. Ehret, L. Stuhl and M. T. Spitler, J. Phys. Chem. B, 2001, 105, 9960-9965.

79. K. R. Mulhern, M. R. Detty and D. F. Watson, J. Phys. Chem. C, 2011, 115, 6010-6018.

80. L. Luo, C.-J. Lin, C.-Y. Tsai, H.-P. Wu, L.-L. Li, C.-F. Lo, C.-Y. Lin and E. W.-G. Diau, PCCP, 2010, 12, 1064-1071.

81. M. S. Kang, S. H. Kang, S. G. Kim, I. T. Choi, J. H. Ryu, M. J. Ju, D. Cho, J. Y. Lee and H. K. Kim, Chem. Commun., 2012, 48, 9349-9351.

82. I. T. Choi, M. J. Ju, S. H. Kang, M. S. Kang, B. S. You, J. Y. Hong, Y. K. Eom, S. H. Song and H. K. Kim, J. Mater. Chem. A, 2013, 1, 9114-9121.

83. N. Robertson, Angew. Chem. Int. Ed., 2006, 45, 2338-2345.

84. E. Palomares, M. V. Martinez-Diaz, S. A. Haque, T. Torres and J. R. Durrant, Chem. Commun., 2004, 2112-2113.

85. K. Sunahara, A. Furube, R. Katoh, S. Mori, M. J. Griffith, G. G. Wallace, P. Wagner, D. L. Officer and A. J. Mozer, J. Phys. Chem. C, 2011, 115, 22084-22088.

86. T. Dos Santos, A. Morandeira, S. Koops, A. J. Mozer, G. Tsekouras, Y. Dong, P. Wagner, G. Wallace, J. C. Earles, K. C. Gordon, D. Officer and J. R. Durrant, J. Phys. Chem. C, 2010, 114, 3276-3279.

87. J. Lim, Y. S. Kwon and T. Park, Chem. Commun., 2011, 47, 4147-4149.

88. J. B. Asbury, N. A. Anderson, E. Hao, X. Ai and T. Lian, J. Phys. Chem. B, 2003, 107, 7376-7386.

89. A. C. Fisher, L. M. Peter, E. A. Ponomarev, A. B. Walker and K. G. U. Wijayantha, J. Phys. Chem. B, 2000, 104, 949-958.

90. T. Trupke, P. Würfel and I. Uhlendorf, J. Phys. Chem. B, 2000, 104, 11484-11488. 